III.

Aus der psychiatrischen und Nervenklinik der Königl.

Charité (Prof. Jolly).

\title{
Ueber die Delirien der Alkoholisten und über kiinstlich bei ihnen hervorgerufene Visionen.
}

Von

Dr. phil. et med. H. Liepmann

in Berlin.

Auf Vorschlag des Herrn Geheimrath Jolly habe ich die im Sommer 1894 in die Königl. Charité eingelieferten Alkoholdeliranten einer eingehenden Beobachtung unterzogen. Dieselbe richtete sich auf das geistige wie auf das körperliche Verhalten der Deliranten. Die Beobachtungen während des Aufenthaltes in der Anstalt wurden durch eingehende Befragung nicht nur des Patienten selbst nach seiner Genesung, sondern auch der Angehörigen über das mittelbar und unmittelbar Voraufgegangene ergänzt, so dass die $125 \mathrm{Krankengeschichten} \mathrm{eine,}$ wie ich glaube, ungewöhnliche Vollständigkeit besitzen. Eine ausführliche Veröffentlichung derselben unterlasse ich und werde nur öfters anf sie exemplificiren.

Die vorliegende Arbeit ist nun zunächst anf die psychische Seite, also die Delirien gerichtet. Dabei sind nicht alle Züge im Seelenleben des Deliranten mit gleicher Anfmerksamkeit behandelt. Gewisse formale Störungen im Ablauf der Vorstellungen sind weniger beachtet, die inhaltlichen in den Vordergrund gestellt. Der erste Theil der Arbeit giebt das Bild wieder, welches die Angaben und das Verhalten der Patienten, durch Nachforschungen in obigem Sinne ergänzt, lieferten. Einzelne Versuche sind eingestreut. Da ich indess fand, dass dieser gewöhnliche Weg, vom Innenleben der Deliranten Kenntniss zu erhalten, 
mit noch zu besprechenden Mängeln behaftet ist, schlug ich noch einen zweiten ein, der von diesen Mängeln frei ist. Es gelang mir artificiell Visionen bei Deliranten auszulösen. Dies Verfahren liefert nicht nur einen Beitrag zur Symptomatologie des Delirium tremens, sondern giebt auch eine Methode an die Hand, um zuverlässigere Aufschlüsse über Ausgang und Wesen der Sinnestäuschungen zu gewinnen, als bei Beobachtung der sportanen Delirien möglich ist. Ich lasse daher der Besprechung der spontanen Delirien einen Abschnitt über artificielle Visionen folgen.

Bevor ich zum Gegenstand schreite, ergreife ich die Gelegenheit, Herrn Geheimrath Prof. Dr. Jolly, sowie Herrn Privatdocenten Dr. Koeppen für ihre andauernde Förderung meiner Untersuchungen meinen lebhaften Dank auszusprechen.

\section{Vorbemerkungen.}

Dass das Delirium tremens eine acute Exacerbation des chronischen Alkoholismus darstelle, ist eine nunmehr unbestrittene Auffassung. Diese Exacerbation kann nun in zwei Formen auftreten.

In der Mehrzahl der Fälle erhebt sie sich zu dem vollen klassischen Bilde der Krankheit mit ihren charakteristischen Symptomen: Zittern, Schlaflosigkeit, Schweiss, Angst, Unruhe, Sinnestäuschungen und anderen psychischen Störungen. In dieser vollen Ausbildung hat sie den angenscheinlichen Charakter einer Geisteskrankheit.

Daneben hat man nun sogenannte "Abortivformen" unterschieden. Näcke*) charakterisirt sie in seiner trefflichen Bearbeitung als ein auf das Prodromalstadium beschränktes Delirium: "Blick unstät, Sprache und Wesen erregt und heftig, Tremor und Delirium kaum vorhanden".

Ich habe geglaubt, den Begriff des Abortivdeliriums etwas schärfer abgrenzen zu müssen. Das Merkmal "Delirium kaum vorhanden" ist zu unbestimmt und überlässt es zu sehr dem Ermessen eines Jeden, was er noch Abortivfall nennen will, was nicht. Es bietet sich dagegen ein Merkmal, welches, soweit es überhaupt der continuirliche Fluss der Erscheinungen zulässt, eine scharfe Grenze zwischen zwei Formen statuirt: das Vorhandensein von Sinnestäuschungen.

Ich verstehe daher im Folgenden unter Abortivfällen solche, in denen zwar Zittern, Schweiss, unruhiger Schlaf und Angst bestehen, aber die psychische Alteration sich nicht bis zur Höhe von Trugwahrnehmungen und Bewusstseinstrübung erhebt.

*) Beiträge zur Lehre des Delirium tremens potatorum. Deutsches Archiv f. klin. Med. XXV. p. 416. 1880 , 
Es fehlt zum ausgebildeten Delirium die starke Bereintächtigung des Vorstellungslebens, daher ist auch der änssere Eindruck einer Geisteskrankheit nicht vorhanden.

Die Uebereinstimmung aber in den übrigen Symptomen, ferner die bei näherem Zusehen auch hier sich oft zeigenden feineren und elementaren Ansätze zu einer Mitbetheiligung der vorstellenden Seite der Psyche, wodurch Uebergangsstufen zu den Fällen mit ausgesprochenen Sinnestäuschungen geschaffen werden, berechtigen, beide Formen als verschiedene Grade derselben Krankheit, des Delirium tremens, aufzufassen. Wo im Folgenden nicht ausdrücklich die Abortivform genaunt wird, ist immer von der ansgesprochenen Form die Rede.

\section{Die spontanen Delirien.}

\section{Affective Seite.}

Als vorherrschender Affect in unseren Fällen muss die Angst bezeichnet werden. Es waren wenig Fälle, in denen sie sich nicht in irgend einem Stadium des Deliriums nachweisen liess. Ein Patient machte in der Charité einen andauernd launigen Eindruck: die Befragung der Frau ergab, dass er zu Hause mit der Axt im Bette gelegen habe, um sich gegen vermeintliche Ueberfälle zn vertheidigen.

Oefters zeigten die Deliranten ein scheinbar heiteres zu Scherzen geneigtes Wesen. Solch ein Patient gestand mir indess nach Ablauf des Deliriums "es sei ein ganz schrecklicher Zustand gewesen". Die Heiterkeit ist dann gewöhnlich eine sehr oberfächliche, die hinter ihr liegende Unsicherheit tritt zuweilen drastisch bervor. So, wenn eln solcher Kranker bei plötzlicher Annäherung mit dem harmlosesten Gegenstande, dem Höhrrohr, dem Thermometer a.s. w. erschreckt zusammenfährt, oder gar um Hülfe ruft „man wolle ihn morden" oder „Feuer anlegen".

Die über die innere Furcht oberflächlich aufgelagerte Heiterkeit hat wohl ihren Grund in den sonderbaren, ungewöhnlichen und unmöglichen Dingen, die dem Deliranten erscheinen, deren lächerliche Seite er in freieren Strunden dunkel empfindet. Kraepelin hat diese eigenthümliche Mischung treffend als "Galgenhumor" bezeichnet.

$\mathrm{Zu}$ Zeiten aber, in denen diese relative Besonnenheit fehlt, bricht dann die helle Angst hervor: der Kranke läuft im Hemde auf die Strasse, will zum Fenster hinausspringen, ruft um Hülfe und ist nicht zu beruhigen. Andauernd maniakalisches Verhalten fand sich unter un- 
seren Fällen nie, wobei natürlich Alles, was nicht streng unter das acute Delirium tremens gehört, ausgechlossen war.

Da nun der Charakter der Sinnestäuschungen meist schrecklicher furchteinflössender Natur zu sein scheint, so erhebt sich die Frage, ob die Angst durch den Inhalt der Sinnestäuschungen bedingt, also secundärer Natur sei oder ob umgekehrt, sie den letzteren ihren beängstigenden Charakter verleihe.

Eine sichere Entscheidung der Frage werden wir später zu besprechenden Versuchen bei Druck auf die Augen entnehmen. Aber schon die einfache Beachtung des spontanen Verhaltens der Deliranten spricht für die letztere Annahme.

Es wäre ja merkwürdig, wenn die Sinnestäuschungen der Deliranten so vorwiegend ein und denselben affectiven Charakter zeigten, ohne doch von diesem Affect bestimmt zu werden. Man müsste dann eine räthselbafte Hinneigung ihres Vorstellungslebens zu Grausigem, Entsetzeneinflössendem annehmen.

Ein Moment könnte geltend gemacht werden, welches geeignet wäre, eine depressive Stimmung generell bei jedem von zahlreichen Sinnestäuschungen Heimgesuchten zu erklären: Die blosse Beobachtung, dass man seinen Sinnen nicht trauen könne, hat für den, der diese Beobachtung an sich selbst macht, etwas aus aller Sicherheit Aufrüttelndes. Die Sinneswahrnehmungen sind die Directiven, die fortwährend der unwillkürlichen Sorge für unsere Selbsterhaltnng zuströmen. Weiss ich nicht, ob ich den nächsten Schritt anf festem Boden thue, oder in einen $\mathrm{Ab}$ grund stürze, ob das Haus vor mir feststeht oder einzufallen droht, so bin ich keinen Augenblick meines Lebens und meiner Gesundheit sicher. Unsicherheit, Misstranen, Furcht sind die natürlichen Folgen.

Indess kommt dieses Moment nur für die Anfangsstadien des Deliriums in Betracht und die Angaben einiger Kranken beweisen in der That, dass es hier in der Aetiologie ihrer Angst eine Rolle spielt. Aber in den vorgeschrittenen Stadien, gerade also denen, in welchen die Angst ihren höchsten Grad erreicht, fehlt das Bewusstsein der Unzuverlässigkeit der Wahrnehmungen und hier lässt die Erklärung im Stich.

Noch entscheidender als diese Erwägungen sprechen die Erfahrungen an Abortivfällen für den primären Charakter der Angst. Bei diesen fehlen Trugwahrnehmungen überhaupt und doch wurde durchweg Angst und Beklemmung zugegeben und bemerkt. Der Delirant Ring wurde dreimal während des Sommers von Abortivdelirien heimgesucht. $\mathrm{Er}$ führte als Hauptbeschwerde an: eine ihm selbst unerklärliche Angst, eine Angst vor etwas Unbestimmtem, eine Angst also ohne Object. 
Bemerkt zu werden verdient, wenn auch zur Zeit daraus nichts weiter geschlossen werden kann, dass die Angst im Delirium sich mit drei körperlichen Symptomen vergesellschaftet findet, die anch die Begleiterscheinungen der physiologischen Angst sind: Zittern, Schweiss und Beschleunigung des Herzschlages. Zum vollen Bilde der physiologischen Angst fehlen die ihr eigenen Darm- und Gefässerscheinungen.

In anderen Psychosen finden wir häufig den Uebergang von der Depression zur Selbstbezichtignng. Diesen oft mühsam zu erschliessenden Zusammenhang offenbarte mir z. B. ein Paralytiker einmal in klassischer ungewollter Selbstanalyse mit den Worten: "Was muss ich nur gethan haben, dass ich mich so ängstige?" Ein solcher Uebergang scheint nun im Delirium tremens nicht stattzufinden. Unter sämmtlichen Deliranten gaben nur zwei an, etwas verbrochen zu haben, der der eine glaubte beim Bäcker Semmeln, der andere Geld gestohlen zu haben. In beiden Fällen wurde aber wahrscheinlich, dass die Ueberzeugung auf Grund von Hallucinationen entstanden war.

Es bleibt also im Delirium tremens bei der Angst und eventuell daraus resultirenden Flucht- und Ahwehrhandlungen. Der Delirant zieht die Conseqenzen seines Gemüthszustandes gewissermassen nach vorwärts in die Richtung der That, nicht nach rückwärts in die der Reflexion und daraus hervorgehenden Wahns.

\section{Das Vorstellungsleben.}

Anomalien der Sinnesthätigkeit.

Die Sinnestäuschungen sind das auffälligste, schon dem Laien bekannte Symptom des Delirium tremens.

Es findet sich eine ganze Stufenleiter von den einfachsten, elementarsten Parästhesien, zu den zusammengesetzten Hallucinationen, die den Kranken in eine völlig andere Welt versetzen.

Sehr häufig wird über die sogenannten subjectiven Empfindungen geklagt. Sie haben zuweilen schon in deliriumfreien Zeiten bestanden, leiten oft das Delirium ein und bestehen hänfig während des Deliriums neben complicirten Sinnestäuschungen fort. Mit den subjectiven Empfindungen im strengen Sinne, bei denen das Empfundene als Zustand des Subjectes empfunden wird und nicht als Glied einer Aussenwelt wahrgenommen, also nicht objectivirt wird (die also nicht eigentlich "Täuschungen" sind), mögen zusammen Täuschungen einfachster Art wegen ihres continuirlichen Anschlusses an jene, als "elementare Empfindungsanomalien" abgehandelt werden. 
Elementare Empfindungsanomalien.

Auf solche elementare Anomalien wurde in etwa 50 Fällen gefahndet. 17 Mal wurde Augenflimmern angegeben. Bald wurde es als solches bezeichnet, bald über "Sehen von Nebel", "Flocken", "Streifen", "schwarzen Füden", einmal über das von "blauen und rothen Bändern" geklagt. Zwei Kranke hatten die Empfindung gehabt, ihnen würde Feuer in die Augen gespritzt, ein dritter etwas Unbestimmtes würde ihm hineingespritzt. B...... fühlte beim Heben einer Last Feuer aus den Augen springen. Da wurde ihm ängstlich und er lief davon.

Ohrensausen und Ohrenklingen gaben 18 (von 50) Patienten an. Einer klagte, etwas "Lebendiges" im Ohre zu haben, ein anderer specieller: "eine Fliege". Ein dritter meinte, es "saust, wie siedendes Wasser". Ein Alkoholepileptiker wollte oft doppelt hören.

In das Gebiet des Tastsinns gehören folgende Sensationen: Ein Delirant fühlte Brennen und Kitzeln am ganzen Körper, ein anderer Spinnengewebe um den Kopf, ein dritter hatte die Empfindung, als ob ihm Mehl auf Hände und Gesicht gestäubt würde, ein vierter und fünfter konnte das Gefühl nicht los werden, als habe er eine "Mütze" bezw. "Kappe" anf dem Kopfe, obgleich sie sich von der Irrigkeit der Annahme überzeugten. Im zweiten Fall bestand dies Gefühl auch noch nach den Delirien. Einem siebenten war es oft, als habe er ein Haar auf der Zunge und als liefen ihm Ameisen im Leibe herum. Auch Brennen und Stechen in den Fingerspitzen kam vor. K.... behauptete, alle Zähne seien ihm lose.

Abnorme Temperaturempfindungen fand ich zweimal. Einmal béstand kaltes Gefühl in Bauch und Waden, das andere Mal abwechselnd Frost und Hitze ohne Fieber.

Der Geruch war nur einmal alterirt. Delirant W..., dessen Delirien aber mit epileptischen Anfällen complicirt waren, hatte im Beginn jedes Anfalles "Schwefel- und Phosphorgeruch". Abnorme Empfindungen in Bezug auf Stellung und Bewegung der eigenen Glieder fanden sich öfter-

Zwei Deliranten glaubten zu fahren, während sie sich im Kasten. bett befanden. Ein dritter zu laufen. In derselben Lage glaubte ein anderer auf dem Schiff zu sein, „wenn Jemand eintrete, schwanke es“.

Alle übertraf eine Delirantin, die zu fliegen wähnte.

Sehr bemerkenswerth war folgender Fall, weil bei ihm die hierher gehörige Täuschung, im Sinne der Beeinträchtigung verarbeitet, das ganze Delirium ausmachte. Schlie.... kam mit starker Bronchitis und Asthma von der inneren Station in höchster Aufregung, man babe ihn dort mit seinem Bett 15 Fuss in die Höhe gezogen and in dieser 
Höhe hängen lassen. Er habe immer das Gefühl gehabt, das Bett kippe um. Auch auf der Irrenabtheilung glaubte er, der vordere Theil des Bettes gehe hoch.

Das gleiche Gefühl hatte noch ein Patient.

Zwei Deliranten glaubten, der Fussboden sänke unter ihnen ein. Der eine wollte dies Gefühl nur rechts haben, also ein Seitenstück zu den unilateren Hallucinationen der höheren Sinne auf dem Gebiete der Bewegungs- und Tastempfindungen.

Dass Alles schwanke und wanke, die Figuren der Tapete oder eines Bildes in Bewegung geriethen, wurde oft namentlich für den Beginn des Deliriums angegeben. Die Erscheinungen scheinen nicht allein vom Auge auszugehen, sondern auch auf Störungen in den anderen Regulatoren des Gleichgewichts zu beruhen. Dafür sprechen die Angaben eines gebildeten und sich selbst gut beobachtenden Patienten. Derselbe erzählte, er habe auf der Strasse die Empfindung bekommen, Alles bewege sich, das Trottoir schwanke und sänke an einzelnen Stellen ein, grosse Pferde- und Männerköpfe hätten sich ihm gezeigt. Wenn er die Brille aufsetzte, verschwanden alle Erscheinungen, bis auf das Schwanken des Bodens.

Geschmackstäuschungen kamen, wohl zufällig, in den von mir untersuchten Fällen nicht zur Beobachtung.

\section{Illusionen und Hallucinationen.}

Die zusammengesetzten Sinnestäuschungen liessen sich zum grössten Theil als sinnliche Illusionen im gewöhnlichen Sinne, d. h. als trügerische Wahrnehmungen von wirklich Vorhandenem erweisen.

Zweifellos sind unter den Illusionen des Deliranten (im weiteren Sinne) auch viele, die nicht sensoriell, sondern intellectuell genannt werden müssen, bei denen es sich also nicht um eine Sinnes-, sondern um eine Urtheilstäuschung handelt. Ergänzt Jemand unvollständige Eindrücke aus der Vorstellung irrthümlich und gewinnt er so die Ueberzeugung von der Anwesenheit eines bestimmten Gegenstandes, so unterliegt er einer Urtheilstänschung. Er hat zu dem ihm zugänglichen sinnlichen Thatbestande den ihm nicht zugänglichen Theil hinzu erschlossen, und zwar fehlerhaft. Erst wenn er den letzteren auch sinn li ch ergänzt, unterliegt er einer eigentlichen oder sinnlichen Illusion. *) Beide Formen finden sich nun bei Deliranten in grosser Hänfigkeit, ebenso wie sie anch bei Gesunden in der Dunkelheit und im Affect

*) In praxi sind die beiden Formen der Täuschung nicht immer mit Sicherheit zu unterscheiden. 
vorkommen. Die intellectuellen Illusionen kommen später zur Besprechung. Hier handelt es sich zunächst nur um die echten sinnlichen Illusionen.

Wenn der Kranke W... angab, dass ihm der an der Wand hängende Anzug zu einer Person, die Schatten von den Bäumen zu Menschen geworden sejen, so kann man zweifeln, ob hier nicht bloss eine Täuschung des Judicium vorlag.

Anders liegt es in folgendem Fall: Hel... sah in der Wanduhr eine kleine Tänzerin tanzen. Sie passte gerade hinein. Sie hatte weisse Strümpfe an und war ein etwa 16 Jahre altes hübsches Mädchen. Sie tanzte schon drei Abende in der Uhr. Aus Furcht, sie würde die Uhr zerbrechen, rief $\mathrm{H}$. ihr zu, sie solle herausgehen und störte durch seine Zurufe derart die Nachbarn, dass er isolirt werden musste.

Er meinte offenbar das Pendel in der Uhr. Hier bestand also nicht nur der Glaube, es sei Etwas da, sondern es wurde deutlich gesehen, in Farbe und Gestalt genau wahrgenommen und beschrieben.

Wie die Uhr, so gab auch eine Klappe an der Wand oft die Anknüpfung für Illusionen, diente gewissermassen als Crystallisationscentrum. Br.. erklärte mir die Klappe als ein Bild von einer reitenden Dame, schwarz auf weiss. Die Verzierung schwarz. „Wenn man eine Weile darauf guckt, sieht es so aus, als 'ob unsere Infanterie kommt, mit rothem Kragen, der Hauptmann springt über die Colonne weg. Jetzt ist das Bild verschwunden". Dann sagte er, scharf ausblickend, "Jetzt habe ich es wieder. Das Soldatenbild ist colorirt. Jetzt drei Tauben, lauter Tauben". "Lebende?" "Nein, gemalte".

Sehr anschaulich schildert der oben erwähnte Meiss.. den ersten Eintritt seiner Beschwerden: „Ich war 4 Wochen stellungslos, habe in der Zeit wenig getrunken und gegessen, war zuletzt zwei Nächte obdachlos. Da fühlte ich morgens plötzlich Unrahe (es folgen die oben gemachten Angaben über Schwanken und Wanken des Bodens etc.). Eine kleine Pfütze wurde mir zu einem Auge, um das sich sofort ein Katzenkopf gruppirte". Bei einem anderen Deliranten begann das Delirium damit, dass die Figuren eines Bildes an der Wand lebendig zu werden anfingen.

Opp...... sah in der Ecke ein junges hübsches Mädchen, dessen Aussehen und Kleidung er genau beschrieb. Aufgefordert, auf dasselbe zuzugehen, näherte er sich einem Kranken, der in der bezeichneten Ecke sass. Auf halbem Wege sagte er entäuscht, „Ach nein, das ist ja eine alte Schraube". Ganz herangekommen, erkannte er, dass er einen bartlosen Kranken vor sich habe. 
Ueberhaupt liess sich die illusionenbegünstigende Wirkung der Entfernung nachweisen.

Ein Delirant sah ein Bouquet. "Wo?" Er zeigte auf ein rothes, etwa 3 Mtr. entferntes Schnupftuch. Als ihm dasselbe auf einen Meter genähert war, sagte er: „Ach nein, es ist ein Schnupftuch!"

Deshalb knüpfen auch die Illusionen mit Vorliebe an Gegenstände der gegenüberliegenden Wand, der entfernten Ecke oder Decke an. In deutliche Sehweite gebrachte, gut charakterisirte Gegenstände, wie eine Uhr, ein Messer, ein Glas werden fast immer richtig bezeichnet, wo überhaupt ein Examen möglich ist. Dagegen werden undeutlich begrenzte Objecte von unbestimmter Form wie Flecke im Bett, Fäserchen, Strohtheilchen auch in der Nähe leicht illusionär aufgefasst. Bekannt ist, dass Flecke oft für Thiere gehalten werden.

Für den Einfluss, den die Deutlichkeit der Netzhautbilder auf die Auffassung der Dinge hat, ist entscheidend die oben herangezogene Angabe eines Deliranten, dass bei Aufsetzen der Brille alle vorher dagewesenen Erscheinungen: "Pferdeköpfe", "Männerköpfe" u. s. w. verschwanden.

Die drei Momente, die als illusionbefördernd zur Kenntniss kamen: Entfernung des Gegenstandes, verschwommene Form desselben, unzureichende Refraction des Auges haben das gemein, dass sie ein undeutliches Netzhautbild liefern. Wir entnehmen also den Beobachtungen die a priori zu erwartende Thatsache, dass undeutliche Netzhautbilder Illusionen begünstigen.

Andererseits wird die naheliegende Vermuthung, die Illusionen des Deliranten beruhten überhaupt wesentlich auf einem Unvermögen desselben scharfe Bilder zu bekommen, also auf herabgesetzter Sehkraft oder aufgehobener Accommodation, widerlegt durch die Erfahrungen, dass wohlcharakterisirte Gegenstände in der Nähe, wenn die Aufmerk samkeitfixirt ist, richtig erkannt werden. Es scheint also, dass beim Deliranten nicht schon andere Bilder als beim Gesunden auf der Netzhaut registrirt werden, dass vielmehr die Abirrung seiner Perception erst im Verlauf der weiteren Processe statt hat, die das Netzhautbild auf seinem Wege zur fertigen Wahrnehmung durchmacht.

Auch der Gesunde hat zahlreiche unscharfe Netzhantbilder, so von einem entfernteren Gegenstande bei mangelhafter Beleuchtung. Aber eine Reihe von Massnahmen sichern ihn für gewöhnlich gegen fälschliche Auffassung des Gegenstandes. Zunächst fixirt er denselben längere Zeit a ufmerksam. Er wendet vielleicht den Kopf hin and her, um verschiedene Ansichten des Objectes zu erhalten. Er zieht Combinationen zu Hülfe. So gelangt er entweder zu einer sicheren Entscheidung 
oder er suspendirt sein Urtheil. Za allen diesen Functionen gehört vor Allem A ufmerksamkeit. Gerade sie aber fehlt dem Deliranten. Er spannt sie nicht genügend intensiv und nicht genügend lange an, um das unter den gegebenen Umständen erreichbare deutlichste Bild zu bekommen. Er kann accommodiren, aber er that es nur nachlässig. Seine Spannung ist schon erlahmt, ehe die gesammten Daten zur Construction des Gegenstandes gesammelt sind, geschweige denn, dass er ihre Vereinigung gehörig vernimmt und sachgemäss assimilirende Vorstellungen zu Hülfe ruft.

Einen sehr schlagenden Beweis hierfür gab folgender Versuch: Ich hielt einem lebhaft hallucinirenden Kranken die Uhr in deutliche Sehweite und fragte ihn "Wie spät ist es?" Er gab eine ganz falsche Zeit an: statt halb zwei, 8 Minuten nach sechs. Bei näherer Beachtung zeigte sich, dass er grossen und kleinen Zeiger verwechselt, die StelI ung derselben aber, sowie die Ziffern richtig erkannt hatte. Nun reicht aber sicher eine Sehschärfe, welche die Ziffern erkennt, völlig: aus, um die Grössendifferenz der Zeiger zu erkennen. Sein Verfehlen beruhte also darauf, dass er von den drei Operationen, deren Combinirung zum Ablesen der Zeit erforderlich ist: Erkennen zweier Ziffern, Erkennen der Stellung der Zeiger zu ihnen und Unterscheidung der Zeiger, die letztere unterliess. Dadurch kam ein falscher Factor in die Rechnung und fälschte auch das Product.

Hier zeigte sich also deutlich ein Hauptfehler in der Wahrnehmung des Deliranten: Die Coordination der elementaren Acte, welche in das, was wir Wahrnehmung nennen, eingehen, wird unvollständig ủnd unzureichend vorgenommen.

Dass in geringem Grade auch die Sehschärfe der Alkoholdeliranten herabgesetzt ist, lässt sich natürlich durch obige grobe Versuche nicht ausschliessen. Im Gegentheil lässt sich wohl denken, dass dies bei Verkennung der Flecke im Bett und entfernter Gegenstände zu den anderen Momenten additionell hinzukommt. Nur soviel erbellt, dass sie nicht die wesentliche oder gar alleinige Ursache der illusionären Perceptionen abgiebt. Ueber die Alkoholamblyopien wird ja mehrfach berichtet. Maré und Nicati fanden dabei Rothblindheit. Nach Hirschberg: soll diese central bestehen und peripher ein pericentrisches Skotom.

Der Augenspiegel hat bisher darüber noch nichts Entscheidendes gebracht. Bei chronischen Alkoholisten fand allerdings Uhthoff $139 \mathrm{mal}$ von 1000 Fällen (13,5 pCt.) temporale Abblassung der Papille. Aber darüber, dass während des acuten Delirium tremens irgend welche vorübergehende Störungen zu diesem doch immerbin geringen Procentsatz hinzukommen, fehlen bisher alle Angaben. 
Lässt sich auch wohl die Mehrzahl der Sinnestäuschungen der Deliranten als Illusionen erweisen, so bleiben doch zahlreiche Hallucinationen übrig, für die sich ein äusseres erregendes Object nicht nachweisen lässt. Principiell ist übrigens der Unterschied der Hallucination von der sinnlichen Illusion gering. Die Illusion ist eine Hallucination, welche in Bestandtheile normaler Wahrnehmung eingewoben sind.

Betrachten wir nun den Inhalt der Sinnestäuschungen! Was sehen zunächst die Deliranten? Rose meint, dass es müssig sei, über den Inhalt der Delirien Feststellungen zu machen. Der Inhalt des Gesehenen variire in's Unendliche. Hält man sich streng an den äusseren Habitus des Wahrgenommenen, so muss man beistimmen. Achtet man dagegen auf den Charakter der Erscheinungen, so lässt sich doch eine gewisse Gleichförmigkeit des vermeintlich Erlebten nicht verkennen. Zudem bemerkt man, dass, wenn auch Alles einmal vorkommen $k a n n$, doch gewisse Dinge und Vorgänge mit auffälliger Constanz wiederkehren. Dazu gehören z. B. Angriffe oder gar Mordversuche von irgend welchen Personen ausgehend; eine besonders grosse Rolle spielt dabei das Geschlachtet-, Gebraten-, Geschmortwerden, ferner Nothzuchtsversuche gegen Frau und Tochter. Diese hier nur zum Beleg einer gewissen Constanz in dem Seelenleben des Deliranten angeführten Beispiele werden uns unten noch aus einem anderen Gesichtspunkte interessiren.

\section{Thiervisionen.}

Das Volk verbindet mit dem Begriff des Delirium tremens bekanntlich seit Alters her die Vorstellung des Sehens von allerlei Thieren, insbescndere Mäusen und Ratten. Hiergegen haben sich neuerdings eine Reihe fachmännischer Stimmen erhoben. Fürstner*) erklärt eine eigentliche Thiervision in der Charite für eine "rara avis". Delasiauve**) hatte nur in weniger als ein Fünftel seiner Fälle Thiervisionen feststellen können. Rose belustigt sich über das Mährchen vom Sehen kleiner Thiere und meint, die Thiere würden überhaupt meist in den Patienten hineingefragt. Z. B. S. 19: „Beim Arbeiterstande mögen Pferde und Ratten bald einfallen; jedenfalls ist es aber durchaus nicht häufig, dass die Kranken spontan solche Auslegungen machen.

*) Fürstner, Archiv f. Psychiatr. VI. 1876.

**) Citirt nach: Mendel, Delirium tremens in Eulenburg's Realencyklopädie. 
Jedenfalls handle es sich wohl bloss um "Erklärungen, die vom Bildungsgrade" etc. abhingen ").

Auch Näcke hatte nur in etwa ein Drittel der Fälle Thiersehen gefunden.

Diesen Einsprüchen, in dem Sinne also, dass Thiervisionen verhältnissmässig selten vorkämen, oder dass sie gar meist in den Patienten hineingefragt seien, widersprechen nun unsere Erfahrungen auf's Entschiedenste. Eine andere Frage, welche später in dem Capitel „Druckvisionen" ihre Beantwortung finden wird, ist die, ob Thiervisionen wirklich in dem Grade überwiegen, in dem sie zu unserer Kenntniss kommen.

Geben wir aber einfach das Bild wieder, das sich dem vorurtheilsfreien Beobachter und Untersucher bietet, so müssen wir die vox populi rehabilitiren. Gehen wir auch nicht soweit, wie Sommer, der in seiner Diagnostik die Thiervisionen „das eigentlich Charakteristische des Deliriums" nennt" $\left.{ }^{* * 5}\right)$, so ergeben doch unsere Beobachtungen das Vorhandensein derselben in der überwiegenden Majorität der Fälle, nämlich bei $70 \mathrm{pCt}$. Und zwar haben wir uns ausdrücklich gehütet, suggestiv vorzugehen, nur wenn Jemand, der keine Symptome mehr zeigte, auf abgelaufenes Delirium verdächtig war, wurde dringender gefragt. Dazu kommt, dass man auch in einem Theil der Fälle, in dem sich keine derartigen Visionen nachweisen liessen, getrost annehmen kann, dass sie da waren. Gerade sie werden zuweilen dissimulirt, weil der Mann aus dem Volke meint, dass erst dadurch sein Zustand zu einem eigentlichen Delirium tremens gestempelt wird, das ja Viele als selbstverschuldetes Leiden nicht wahrhaben wollen ${ }^{* * *}$ ). In mehreren Fällen liess sich absichtliches Inabredestellen oder auch Vergessenhaben von Thiererscheinungen nachweisen. So verneinte ein Patient mit grosser Bestimmtheit, jemals Derartiges gesehen zu haben. Das später eingelaufene Attest des Arztes, der ihn eingeliefert hatte, gab dann an, dass ihm Krebse und andere Wasserthiere anf der Polizei erschienen seien. Eben dahin gingen öfter die Mittheilungen der Frauen.

Delirant Stie ... wollte absolut keine Thiere geseben haben. Wenige Stunden darauf erzählte er uns "draussen im Teich seien Enten".

Von den Thieren, die unsere Deliranten gesehen, liesse sich eine

*) Rose, Delicium tremens and Delirium traum. Deutsche Chirurgie, Liefer. 7. 1885.

**) Diagnostik der psychischen Krankheiten. 1894. S. 74.

***) Wir werden später sehen, wie diese Dissimulation überwogen wird durch ein anderes Moment, welches zu einer Ueberschätzung der Rolle der Thiere im Delirium führt. 
ganze Zoologie zusammenstellen. Fast jede Klasse ist vertreten. Am häufigsten sind Mäuse, Ratten, Käfer, Würmer, Hunde, Katzen und Vögel. Aber auch grössere und vornehmere Thiere kamen vor: Pferde, Schweine, Kühe, Kameele, Elephanten. Selbst der stolze König der Thiere feblte nicht.

Auch eine Reihe phantastischer Thiere wurden gesehen. Mehrfach begegneten wir der Angabe: "Thiere, die es gar nicht giebt" oder "Phantasie-Vögel". Ein Patient sah ein Doppelthier, das an die homerische Chimära erinnerte: "vorn ein Hirsch, hinten ein Elephant".

Waren es keine lebenden Thiere, so waren es ausgestopfte oder gemalte. Oft sollten sie nur im Traum gesehen sein, was aber meist angezweifelt werden darf, da ia der Delirant selten einen eigentlichen Schlaf hat*).

Dabei rechnen wir nicht za den Thiervisionen Fälle, bei denen Thiere nur als Bestandtheile einer ganzen Scenerie auftraten, also wenn etwa Fuhrwerke, Kavallerie, ein Leichenzug hallucinirt wurde, wozu natürlich Pferde gehörten. Gewöhnlich sind es ganze Haufen oder Rudel von Thieren. Schich... sah eine ganze Compagnie Stachelschweine, Fen... sah Rehe, Ziegenböcke; letztere zu sechs angespannt, machten Wettrennen. Ein Dritter sah Schwalben und Hunde, und zwar „Dachshunde, Schäferhunde, Feldhunde, Wolfshunde". Ker.... sagte auf die Wand zeigend: „Dort wohnen auch Leute". Auf die Frage wo? antwortet er: „Da oben zwischen das Grüne, wo die Frösche, Kröten und Mäuse sind. Es sind auch Vögel, Wasservögel, Kühe und Ziegen da". Zugleich ein Beweis, wie spontan Derartiges vorgebracht wird.

Pet... beschrieb die Geschöpfe, die er sah, als „Dinger mit einem dicken Kopf, kleine Deibel's, die um ihn herumhuppten, wahre Missgeburten". Er habe eine Frau gefragt, was das für Thiere seien. Sie habe geantworet: "Mein Mann hält sich so dreckige Thiere". Die Frau

*) Was auf die eigenen Angaben der Kranken, dass sie geträumt oder geschlafen hätten, zu geben ist, zeigt folgender sich oft wiederholender Fall: Ha... gab an, er habe die ganze Nacht durch geschlafen und zwar in seinem Bett. Der Wachbericht enthält nun Folgendes: H. war um 9 Uhr 30 Abends isolirt worden.

10-11. Patient steht an der Thür und klopft.

11-12. Patient tappt an den Wänden herum.

12-1. Klopft und will heraus.

1-2. Geht in der Zelle umher.

2-3. Tastet an der Wand.

3-4. Sitzt auf der Matratze, ist ruhig.

4-5. Steht in der Ecke, ist ruhig. 
erzählte ausserdem, ihr Mann habe 2 Staare und 13 Junge gesehen. Zuweilen sind es vereinzelte Thiere. Odit... spielte im Bett mit einem Häschen. „Komm Häseken, komm".

Bart.... sah öfter einen gelben Hund um sich herumspringen. Tet... erzählte, als er klar geworden, er habe zu Hause in einem leeren Vogelbauer Kanarienvögel gesehen. Seine Frau habe ihm dann gesagt: "Es flimmert Dir bloss vor den Augen". Alle Uebrigen übertraf Schm..., der andauernd der Meinung blieb, er sei "in der Thierarzneischule". Er habe Pferde im Garten und Wachsaal gesehen.

Diese Beispiele liessen sich bis zur Ermüdung vermehren.

Damit ist nicht gesagt, dass die Thiere gewöhnlich das eigentlich Beherrschende des Deliriums ausmachen. Sie kommen oft nur vorübergehend vor, während ein anderer Wahn im Vordergrund steht. So sah ich einen Deliranten in der Isolirzelle lebhaft mit eingebildeten Personen sprechen und gesticuliren. Häufig unterbrach er seine Reden, blickte zu Boden, bewegte die Augen, als ob er etwas Beweglichem folge und trat dann stark auf den Boden, wie, um ein Thier todtzutreten. Dann verfiel er wieder in die unterbrochenen Delirien.

Ueberhaupt lassen die Bewegungen der Kranken oft keine andere Deutung zu, als dass sie ein Thier abwischen, fangen, tödten wollen.

Pard..... machte solche Fangversuche. Gefragt, wonach er jage, erwiderte er "nach Maikäfer": „Die kann man aber Keinem geben, sie zergehen gleich wieder in der Hand!" Hier betheiligte sich also der Tastsinn nicht an den Hallucinationen des Gesichts. Ueberhanpt werden die Thiere meist gesehen, seltener gefühlt, noch seltener gehört.

\section{Charakter der Visionen.}

Wegen der Bedeutung, welche die Thiere beim Delirium tremens in der Meinung des Volkes haben, ihrer thatsächlich auffälligen Rolle und der gegen dieselbe gerichteten Polemik habe ich sie in einem besonderen Capitel abgehandelt. Indess wäre es eine höchst äusserliche Eintheilung des Inhalts der Delirien, wenn wir zum principium divisionis die Zugehörigkeit zu einem der drei Naturreiche erhöben.

Psychologisch wichtiger ist folgender Unterschied im Auftreten der Hallucinationen.

Ein Theil derselben bildet zusammenhanglos aneinander gereihte Bilder, Wandelbilder ${ }^{*}$ ), zuweilen so von den Kranken selbst bezeichnet,

*) Vergl. Jolly's Bemerk. in der 80. Vers. d. psych. Verein in Berlin in der Discussion über Paranoia. Allg. Zeitschr. f. Psychiatrie. LI. 1. 1894. S. 193. 
die anderen ordnen sich zu zusammenhängenden Erlebnissen an einander. Beide Formen kommen übrigens häufig bei demselben Patienten vor. Die letzteren hänfiger, aber durchaus nicht ausschliesslich, Nachts. Als reine Beispiele von Hallucinationen müssen wir uns an die Wandelbilder halten. In die zusammenhängenden Erlebnisse gehen, wie wir sehen werden, ausser den Sinnestäuschungen noch andere Elemente ein.

Solche Wandelbilder hatte Wei.... Er sah einen grossen Hund, dann einen Jungen, der sich in eine Schlange verwandelte, in den Kuppen der Bäume Mädchenköpfe.. Glaubte dann die Braunschweiger Husaren zögen vorüber mit Musik.

Der schon erwähnte Ker.... sah nacheinander an der Wand: Leute und Häuser, im Grünen Kröten, Vögel, Kühe, ein ganzes Dorf, ein richtiges Panorama, 5-6 Mäuse, schliesslich nur noch einen Mann mit einem Buch.

Dab ..... „Jetzt kommen sie von der Parade zurück. CavallerieMusik ist nicht dabei. Jetzt sind Bäume vor, jetzt sehe ich nichts, nur ein Schutzmann reitet vorüber". Er glaubt dann, Geld in der Hand za haben.

Bezüglich des physischen Charakters der Gesichtshallucinationen haben die später mitzntheilenden Versuche zuverlässigere Aufschlüsse gebracht, als die ja zum grossen Theil aus nachträglichen Berichten bekannt gewordenen spontanen Täuschungen. Folgendes möge schon hier aus den Angaben der Kranken verzeichnet werden: Personen, Thiere und Gegenstände hatten meist wirkliche Grösse. Ueberlebensgrösse wurde nur von einem Patienten angegeben. Jed ...... sah einmal einen Kerl "so gross wie das Zimmer" und noch einmal Männer "so hoch wie die Decke".

Wo sonst Abweichungen von der Lebensgrösse vorkamen, war es in der Richtung der Verkleinerung.

Pet... sagte nach der Krise: "Gestern sah Alles viel kleiner aus". W.... sah Katzen unter Lebensgrösse, Witt Hündehen und Kätzchen fingergliedlang. Der Delirant, der obige Riesenerscheinungen hatte, sah daneben "ganz kleine Männeken's in den Gardinen".

Das Gesehene war gewöhnlich plastisch. Aber auch "Bilder" in engerem Sinne, flächenhafte Erscheinungen traten mehrfach auf. Das Meiste wird farbig gesehen.

Bei Nacht spielen aber "schwarze Männer, dunkle Gestalten, Deibel's" eine grosse Rolle. Die grauschwarzen Ratten und Mäuse scheinen gerade häufiger am Tage gesehen zu werden. Localisirt wird Alles nach Aussen an einen ganz bestimmten Ort. Bald nah, bald weit. Ob es sich bei Dingen, die in unmittelbarer Berührung mit dem Körper wahr- 
genommen werden, um Gesichts- oder Gefühlstäuschungen handelt, ist oft schwer zu entscheiden. Dass das Gesehene meist in Bewegung sei, ist mit Recht von anderen Autoren betont worden.

Was den psychischen Charakter der Wandelbilder betrifft, so handelt es sich hier im Vergleich zu dem Inhalt der zusammenhängenden Erlebnisse noch verhältnisnmässig oft um nicht unangenehme Dinge. Zwar sind es auch hier oft Fratzen, die den Kranken verhöhnen, Thiere, die ihn beängstigen oder anwidern, feindliche Gestalten, aber häufig auch Militär, Wagenzüge, Landschaften und Aehnliches gleichgültigen oder vergnüglichen Inhalts. Nur ein Delirant gab an, dass er das sah, woran er dachte. Er war Alkoholepileptiker.

\section{Die Auditionen.}

Dass die Hallucinationen der beiden höheren Sinne die vorherrschenden sind, ist bekannt. Hallucinationen des Tastsinns, Geruches u.s. w. sind schon bei den elementaren Anomalien erwähnt. Es fragt sich nun, wie gross ist die Betheiligung der Gehörshallucinationen. Es liessen sich in 40 pCt. der Fälle sichere Gehörstäuschungen nachweisen. Manche Gehörstäuschungen mögen der Beobachtung entgehen. Auffällig ist aber sicher, dass die eingebildeten Vorgänge öfter nur von ihrer sichtbaren Seite geschildert werden, Mittheilungen indess darüber, dass die gesehenen Menschen gesprochen, die Thiere gebrüllt u. s. w. hätten, in erheblich weniger, als der Hälfte der Fälle vorkamen. Das gänzliche Fehlen von Gesichts- und Gehörshallucinationen bei Bestehen von Sinnestäuschungen $\mathrm{kam}$ vereinzelt vor. So in dem Fall von Schlickeisen, dessen einzige Täuschung darin bestand, dass er sich sammt Bett in die Höhe gezogen fühite.

Bemerkenswerth ist nun, dass sich fast nie eine vereinzelte Gehörshallucination zwischen Gesichtshallucinationen eingestreut fand. Wer vielmehr überhaupt Gehörstäuschungen hatte, hatte sie wiederholt. Es handelt sich also nicht um zufälliges Auftreten, sondern gewisse Naturen scheinen zu Gebörshallucinationen zu neigen. Man kann demnach eine Kategorie rein visionärer und visionär-auditionärer Deliranten unterscheiden.

Wei... hörte Nachmittags seine Freunde auf dem Hofe und im Keller seinen Namen rufen. Sie verlangten unter Drohungen seine Flasche. Als er zum Fenster heraussah, erblickte er sie auch. Als er aber auf den Hof kam, waren sie nicht da. Dann hörte er auf dem Wege nach der Charité wieder seine Freunde schimpfend hinter sich. Sie riefen Ludwig and Aehnliches. Er sah sie aber nicht.

Opp...... hat Kinder ein Lied, über ihn, den ,berühmten Opp......", 
singen gehört. Das lied handelte daron, dass er 6-7jährige Mädchen gemissbraucht habe. Während er sich hierüber bitter beklagt, hört er das Lied wieder ans einer Ecke des Saales ron einem Mädchen singen. Am nächsten Tage wandte sich Patient öfter um und fragte: „Was?" Ein ander Mal: „Wer will mich morden?"

Weid .... hörte Nachts Eulen und andere Raubvögel schreien, kroch dann unter die Bettdecke. Dann am Tage: Musik, die Wacht am Rhein durcheinander mit Heil Dir im Siegerkranz. Später hört er Lyra und Leierkasten spielen. Auch war es ihm öfter, als ob Jemand durch die Wand zu ihm spräche.

Diejenigen, welche in den deliriumfreien Zeiten oder zu Beginn des Deliriums an Ohrensausen litten, waren besonders zahlreich unter der zweiten Kategorie vertreten.

Sehr oft handelt es sich auch bei Gehörstäuschungen um Illusionen.

Gehört wurden meist Drohungen und Beschimpfungen. Aber, wie schon einige Beispiele zeigten, gelegentlich auch Musik oder gleichgültige Dinge. Von 50 Gehörshallucinationen, die ich notirt habe, waren 29 bedrohlicher, beleidigender oder sonst quälender Natur, 10 mal wurde Musik oder Gesang gehört,

11 mal Gleichgültiges (Schnarchen, Miauen, Reden, Rufen des Namens u. s. w.).

Die Stimmen wurden immer nach Aussen verlegt und meist laut und nah gehört. Selten in Flüsterton.

Bei Gehörshallucinanten fiel mir auch auf, dass sie sich oft verhörten.

Tr... fragte ich: "Warum sind Sie so anfgeregt?" "Gerückt? Gerückt bin ich noch nie". Küch........ verstand statt "Krämpfe" erst Krebse, nach Wiederholung "Kremser".

\section{Die Realität des Wahrgenommenen.}

Wie stellt sich das Bewusstsein des Deliranten zu dem Wahrgenommenen, insbesondere, um uns an das Wichtigste zu halten, zu den Visionen? Durchaus nicht überall gleichartig. Es lässt sich vielmehr eine Art Stufenleiter für den Glauben an die Realität des Gesehenen aufstellen. Die unterste Stufe stellt die unmittelbare Erkennung der Erscheinungen als Täuschungen dar. Rei.... sagte: „Jetzt sehe ich Männerköpfe und Pferdekőpfe an der Wand and höre Hülferufe. Weiss aber, dass Alles Einbildung ist".

Die Frau des Deliranten Mei ..... erzählte, dass ihr Mann zu Hause gesagt habe: "Da kann man sehen, was die Krankheit ist. Jetzt sehe ich rechts Ratten, pass' mal auf, gleich werde ich links welche sehen. 
Richtig, da sind sie!" Also volles Krankheitsbewusstsein, unmittelbare Erfassung der Visionen als pathologischer Eigenproducte!

Bart... gab nach Genesung an, er habe kleine Hündchen und Kätzchen an seinem Bette gesehen. "Ich habe aber nichts davon gesagt, weil ich wusste, dass es Einbildung war".

Oefter kommt die Einsicht in den imaginären Charakter der Gesichte erst mittelbar durch Correctur mittelst anderer Wahrnehmungen und Erwägungen.

Die oberste Stufe bildet der Glaube an die volle Realität des Gesehenen, der in der Mehrzahl der Fälle auf der Höhe des Deliriums besteht. Das Gesehene hat gleiche, ja zuweilen höhere Geltung, als die Wirklichkeit.

Dazwischen schiebt sich nun eine interessante Varietät ein. Ein Theil der Deliranten ist zwar noch urtheilsstark genug; um die Möglichkeit der abenteuerlichen Erscheinungen als Glieder der sie umgebenden Wirklichkeit zu verneinen. Dem, dass etwa ein Löwe, eine Hexe oder Aehnliches wirklich in der Charité umherlaufe, widersetzt sich noch ihr Urtheil. Aber andererseits reicht es nicht aus, um die Subjectivität der Eindrücke zu erkennen. Da bietet sich dann ein merkwürdiger Ausweg: das Gesehene wird für Schauspiel, Vorstellung, Veranstaltung oder allgemeiner ausgedrückt für Spiel gehalten. Was in den Rahmen der wirklichen Umgebung absolut nicht passt, wird in den loseren einer zweiten freieren gewissermassen künstlerischen Wirklichkeit eingeordnet. Dieser Begriff vom vermeintlichen Spiel nimmt keinen geringen Raum in der Psyche des Deliranten ein.

Kiel... erzählte ein grosses Erlebniss. Er sah 50 todte Menschen auf der Mauer liegen, zahlreiche Gendarmen. Beides verschwand, als er darauf losging. „Da ich nun", gab er selbst an, "viel in Circussen gearbeitet habe und in Betreff der Verwandlungsgeschichte Bescheid wusste, ging mir ein Licht auf. Maschinisten hatten das gemacht und auch die Kinkerlitzchen, die nun losgingen, nämlich zahlreiche Thiere, darunter ein grosser Flunder mit abnehmbarem Kopf". Das Ganze erklärte er als Theater, das man gemacht habe, um ihm,graulich zu machen, um seinen Muth zu erproben". Noch drei Tage lang blieb er dabei. Dass Säufer Bilder sehen, wisse er, aber das Theater sei wirklich gewesen.

Fra... erzählte von Hexenerscheinungen, die Frennde von ihm mittelst einer Spiegelmaschine auf gegenüberliegende Häuser geworfen hätten. Fri... erzählte von Heinzelmännchen, die seinen Tod vor ihm aufgeführt und auch allerhand andere Aufzüge veranstaltet hätten. 
Opp..... wohnte einer Vorstellung bei, in der nach ausgestopften Vögeln geschossen wurde.

Bei einzelnen ähnlichen Visionen darf man wohl den „Aufzug“" oder das "Theater" nicht im obigen Sinne als Deutungsversuch, also gewissermassen als Abfindung der noch vorhandenen Besonnenheit mit dem Wahrgenommenen auffassen, sondern muss in ihnen einfach den Inhalt des Wahrgenommenen sehen. Ebenso gut wie sich der Delirant in einer beliebigen anderen Situation sieht, könnte er sich auch einmal als Zuschauer einer Vorstellung sehen. So kann es, wenn Kerssen ein grosses Schützenfest in der Charité beschrieb, zweifelhaft bleiben, in welchem Sinne dies zu deuten ist. Aber abgesehen davon, dass Einzelne die Auffassung vom Spiel direct als Erklärung angaben, macht der Umstand, dass sich Deliranten fast stets in unangenehmer Situation sehen, es unwahrscheinlich, dass sie sich so häufig in der vergnüglichen Lage eines Theaterbesuchers etc. wirklich von vornherein wähnen sollten, legt vielmehr auch in der Mehrzahl der zweifelhaften Fälle die Vermuthung nahe, dass es sich um bewusste Erklärung der Phänomene handelt.

Dass ein Delirant seine Trugwahrnehmungen von den Eindrücken der Wirklichkeit unterschied, sie aber weder als "Spiel", noch als Einbildung betrachtete, sondern, wie es in anderen Psychosen geschieht, als göttliche Offenbarungen oder sonstige Eingebungen übernatürlicher Art ansah, kam nicht vor.

Zuweilen lehnt sich noch ein Maass von Besonnenheit gegen das Wahrgenommene auf, ohne aber auch nur in der eben beschriebenen Weise durch Verweisung unter das "Spiel" seiner Herr zu werden.

Da.... sah 200 Wagen den Berg herauffahren. „Staatsfuhrwerke. Einer mit 6 Schimmeln; die Schimmel haben Holzbeine, wahrscheinlich solche, die der Tischler gemacht hat. Sie fahren auf den Bäumen herum". "Das geht eigentlich nicht mit rechten Dingen $z^{\text {". }}$ Aber er blieb dabei, es sei so.

Merkwürdig ist, wie derartige Deliranten die Gelegenheit, die Täuschung eines Sinnes durch den anderen zu corrigiren, ungenützt lassen. Von Pard.... war schon erwähnt, dass er Maikäfer sah, die er selbst als solche schilderte, „die man keinem geben könne. Sie vergehen gleich in der Hand". Statt also aus dem Ausbleiben einer Tastempfindung zu schliessen, dass die Gesichtsempfindung subjectiv sei, verlegt er eine Absurdität in das Object.

Br.. meinte: „Es ist so komisch, manchmal sehe ich etwas, und wenn ich zugreifen will, ist es weg. So ist es aber mit jedem Gegenstande. Ich sehe Spazierstöcke und wenn ich hingreife, sind sie weg". 
Man beachte, dass hier die Suggestibilität des Deliranten nicht ansreicht, den Tastsinn zur Anerkennung eines gesehenen Objectes zu bringen.

Die zusammenhängenden hallucinatorischen Erlebnisse.

Hallucinationen und Sinnesillusionen sind die Grundlagen dieser interessanten Erlebnisse. Indess gehen noch andere Elemente in dieselben ein. Sehen wir uns zunächst diese Erlebnisse an. Es sind meist solche, in denen der Delirant mit seinen Nächsten eine leidende Rolle spielt.

Es handelt sich fast durchweg um Verfolgungen, denen der Kranke ansgesetzt war. Wie schon erwähnt, spielt das Ermordet-, Geschlachtet-, Gebraten., Geschmortwerden eine grosse Rolle. Die Frau oder Tochter wird genothzüchtigt, nachdem man den Kranken selbst gefesselt, weggeschleppt, eingesperrt hat. Oft knüpfen diese Geschichten an die Isolirung des Kranken durch die Wärter an. Aber zuweilen liegt gar keine äussere Anknüpfung vor. In stiller Nacht hört der Delirant Stimmen vom Hofe, die ihm drohen, oder er sieht „Männe. ken's", die mit geschwungenen Säbeln und Beilen auf ihn losgehen. Diese Vorgänge spielen sich mit Vorliebe Nachts ab. Aber sie fehlen durchaus nicht am Tage. Ich schildere hier nur einige derartige Wahnerlebnisse, deren Zeuge ich selbst am hellenlichten Tage war.

Hen..., der sich am 24. Mai einen Schuss in die Herzgegend beigebracht hatte, fängt an 8. Juni an zu deliriren. Im Bett liegend, behauptet er, der Wärter, welcher ruhig abseits stand, wolle auf ihn schiessen. Er habe mit Flüssigkeit geladen. „Meine Tochter habt ihr schon genothzüchtigt und dann vergiftet. Meinen Vater habt ihr auch umgebracht". Auf meine Frage "Auf welche Weise?" „Er ist todtgeschossen worden, der Qualm steht ja noch im Garten. Das kann ich Alles beschwören". (Wüthend) "Wenn ich meinen Rerolver hier hätte, hätte ich Euch schon alle weggeknallt. Solche Brutalität, solch armes Kind".

Carl Schm..., der eben noch leidlich ruhig im Bett gelegen hatte, springt während der Visite plötzlich heraus, läuft zum Arzt, fleht ihn weinend um Hülfe an, man wolle ihn schlagen, ihn umbringen. Man solle ihn nicht verlassen. Alle Bemühungen, ihn zu beruhigen, blieben erfolglos.

Hön..., der, wie er erzählt, schon zu Hause von einem Teufel Nachts Besuch erhalten hatte, verlangte am 3. Juli heftig seine Kleider. Als man ihm Selterwasser reicht, ruft er in höchster Erregung um Hülfe, „Mutter, Mutter, zu Hülfe". Auf Versuche, ihn zu beruhigen, erwidert er, man wolle ihn schlachten. "Das Messer haben Sie schon in den Händen".

Als er wieder klar geworden war, erzählte er, er sei der Meinung gewesen, man wolle seine Wohnung ausräumen (eine übrigens öfter wiederkehrende Vorstellung). 
Zahlreich sind die Mittheilungen von Franen der Deliranten über derartige Scenen. Die Frau des Patienten Le... erzählte:

„Vor 3 Jahren hatte L. schon einen Anfall, sah Gestalten, fürchtete umgebracht zu werden, es ging aber vorüber. Vor 8 Tagen kam wieder ein $\Lambda$ nfall. Es wackele Alles, man wolle ihn sehlagen. Er vertheidigte sich gegen Thiere. Die Medicin, die ihm der Arzt gegeben habe, wollte er plötzlich nicht weiternehmen. Man wolle ihn vergiften. Behauptete, er solle in den Ofen gesteckt werden. Schlief kaum einen Augenblick. Lief aus Angst Nachts im Hemde auf die Strasse. Man warf ihm seine Sachen nach. Er klagte dem Wächter, man wolle ihn umbringen, seine Frau wolle ihn vergiften. Schliesslich kroch er in einer Budike unter. den Ladentisch und wurde dort festgenommen".

Die eigenen Erzählungen, welche die Kranken über solche Schreckerlebnisse in höchstem Ernst und nnerschütterlichem Glauben an ihre Realität machen, muthen an, wie die Erzählung eines Traumes, obgleich unsere Beobachtungen und die Angaben der Angehörigen beweisen, dass es sich meist um Wacherlebnisse handelt. Ihrer Aehnlichkeit wegen mit Träumen hat man sie treffend als Wachträume bezeichnet.

Das Schanerlichste, was die Phantasie ersinnen kann, wird gesehen und gehört. Sind es keine tragischen Ereignisse, so mindestens peinliche, quälende Verlegenheiten: Die Kleider werden ihnen weggenommen, sie wollen kutschiren, werden aber vom Bock heruntergetrieben, sie wollen fahren, aber andere Fuhrwerke fahren ihnen fortwährend in die Quere. Oft ist schwer zu entscheiden, wie viel von wirklichen Ereignissen in die Geschichte eingesponnen ist. Die Isolirung giebt sicher häufig einen Anknüpfungspunkt für viele derartige Geschichten.

Br.. erzählt von der Nacht, während der er isolirt war, er sei im Keller gewesen (wie denn überhaupt die Zelle, obgleich im gleichen Stockwerk wie der untere Wachsaal, häufig als Keller bezeichnet wird, wohl wegen der hohen Lage des Fensters). Er wüsste nicht, wie er hereingekommen sei, da die Thüren verschlossen waren. Dann sei sein Vater und seine Frau vor den Keller gekornmen und hätten ihm Kaffee und Kuchen angeboten. Aber sie hätten diese nicht durchreichen können, da die "Latten dazwischen waren". Er habe sich nun vergeblich die Nacht hindurch gemüht, aus dem Keller zu den Seinigen zu gelangen. Schliesslich musste die Thür mit Gewalt weggedrängt werden.

Das Hinwegsetzen über die Gesetze der Wirklichkeit, das ungebundene Walten der Phantasie haben diese Wachträrume gemeinsam mit den eigentlichen Träumen des Schlafes. Das Groteske, Bizarre herrscht.

Kl... sah am Tage in der Leipzigerstrasse eine gewisse Antonie, mit der er früher Beziehungen unterhalten hatte, von oben herniederschweben. Er sah 
ihre seidenen Kleider. Sie forderte ihn auf zu sterben, drohte, ihm sonst den Bauch aufzuschlitzen. Sie verlangte von ihm, er solle katholisch werden. Sie liess Sonnenstrahlen auf ihn los, worauf er abwechselnd gelb, roth, grün wurde. Wo die Strahlen seine Haut trafen, hatte er Nässegefühl. Verstorbene riefen ihn. Es blitzte und donnerte. Er stand furchtbare Angst ans. Er wurde zur Charité gebracht. Hier glaubte er in der Hölle zu sein. Fr bildete sich ein, Gott habe ihn zur Strafe dahin gebracht, weil er Antonie zugesagt habe katholisch zu werden. Er sah deutlich eine grosse Pfanne, in der er geschmort werden sollte. Daneben stand seine Mutter und weinte.

Diese Geschichte erzählte der Patient nach seiner Genesung. Den letzten Theil, seinen Aufenthalt in der "Hölle", seine Furcht "gesehmort" zu werden, hatten wir Gelegenheit, selbst zu beobachten. Uebrigens gestand er, wirklich mit einer Katholikin verkehrt zu haben, die von ihm geheirathet sein wollte und als er sie verliess, ihm gedroht habe: "Dir thue ich noch einmal etwas an!"*

Ein Patient und eine Patientin wollten gestorben sein im Delirium. Die Rie... behauptete, sie habe einen Herzsehlag bekommen und sei im offenen Sarge begraben worden. Ein Herr hat sie dann elektrisirt und wieder zum Leben gerufen. Dieser Herr wurde dann von vier Schutzleuten hinausgeworfen.

Sicherlich ist nun nicht Alles, was der Patient so „erlebt" hat, auch wirklich gesehen, gehört oder gefühlt. D. h. die Erlebnisse gehen nicht gänzlich in Hallucinationen und sensorischen Illusionen auf.

Allerdings von dem Vorhandensein einer dritten Art von Bildern, die Rose als Phantasmen aufstellt, konnte jch mich bei den Deliranten nicht überzeugen. Diese Phantasmen sollen nach Rose*) farblose, nicht plastische Bilder sein. „Man sieht beispielsweise Menschen handeln und hört zugleich ihre Reden, ... . es sind eben keine wirklichen plastischen, leuchtenden Wahrnehmungen." Sie sollen nach Rose erst in einem dritten Stadium, dem der Agitation, zu dem es meist nicht komme, auftreten, und gerade den höchsten Grad der Bewusstseinstrübung bedingen. "Durch sie wird der Kranke in eine andere Welt versetzt."

Nun laufen zwar wohl unter die farbigen und körperlichen Visionen der Deliranten auch zuweilen dunkle oder flächenhafte Bilder unter. Aber weder liess sich feststellen, dass dies mit Vorliebe oder gar ausschliesslich auf dem Höhepunkte der Delirien eintrat, dass dadurch also erst die gänzliche Desorientirung bedingt werde, noch sind solche Bilder qualitativ von den übrigen echten Sinnestäuschungen zu trennen. Ebensowenig, wie eine Photographie ein weniger reales Sinnesding ist, wie eine bemalte Statue, hat eine flächenhafte oder silhouettenhafte Vision weniger den Charakter der echten Trugwahrnehmung, als eine dreidimensionale "leuchtende".

*) 1. c. S. 17 .

Archiv fi. Psychiatrie. XXVII. 1. Heft, 
Was Rose dabei vorschwebt, nur durch die öfter angeführten Momente des Nichtleuchtenden, Farblosen, Unplastischen falsch gekennzeichnet ist, sind offenbar einfach lebhafte Erinnerungsvorstellungen. Denn er sagt: "Es sind das eben reine Vorstellungen von Empfindungen" und Aehnliches. So Vorgestelltes ist aber durchans nicht farblos oder unkörperlich. Wenn ich mir eine Stange Siegellack vorstelle oder einen Kanarienvogel, so stelle ich mir erstere roth, letzteren gelb, beide körperlich vor.

Solche Vorstellungen vom psychologischen Charakter der Erinnerungsvorstellungen spielen nun allerdings in den Delirien eine Rolle. Aber sie unterscheiden sich in Nichts von den gleichen Vorstellungen bei Gesunden, und bedürfen daher keiner besonderen Bezeichnung als Phantasmen, um so weniger, als sie nicht für sich und direct za Täuschungen Anlass geben. Sie stellen sich nur als psychologisch unerlässliche Elemente jedes Urtheils in den Dienst der Urtheilstäuschungen, die wir schon als intellektuelle Illusionen kennen gelernt haben. Solche gehen nun allerdings in die Erlebnisse mit ein.

Damit z. B. bei dem Deliranten die Idee entstehe, er werde verfolgt, braucht nicht immer eine Waffe oder aggressive Bewegung gesehen werden. Es genügt, dass schwarze Gestalten erscheinen. Sofort bemächtigt sich des Deliranten unter dem Einflusse der Angst der Gedanke, sie wollten ihm etwas anhaben. Er ergänzt das Gesehene durch Vorstellungen und kommt so zu einem Urtheil. Es liegt also hier eine Urtheilstäuschung vor. Nun komme zu den schwarzen Gestalten als neue Sinnestäuschung etwa der Anblick eines Feuerstrahls (welche elementare Wahrnehmung wir mehrfach angetroffen haben) hinzu. Sofort bildet sich die Ueberzeugung, die Männer spritzten ihm Feuer in das Gesicht. Es sind also ,Teufels!" Es bemächtigt sich seiner zu der primären eine furchtbare secundäre Angst, die nun weiter dazu beiträgt, ihn seine objectiven und subjectiven Sensationen ungenügend und falsch auffassen zu lassen. Der durch den Lärm gestörte Nachbar rufe ihm nun etwas zu: er hört eine wörtliche Bedrohung seiner Verfolger heraus! Es kommt so zu einem zusammenhängenden Schreckerlebnisse, indem zwischen die Hallucinationen und Illusionen irrige Annahmen, übereilte nicht begründete Urtheile interpolirt werden. Diese sind dann weiter für die Deutung des Folgenden bestimmend. Sie bringen den Zusammenhang in das Ganze.

So wird es verständlich, wie auch peripher ausgelöste Hallucinationen sich zu einem zusammenhängenden Erlebniss ordnen können. Die auf Grund der einen Trugwahrnehmung entstandene Ueberzeugung wirkt auf die Auffassung der folgenden ein. Die bizarren, sprunghaften Wendun- 
gen, die dann wieder diese Erlebnisse trotz eines äusseren Zusammenhanges zeigen, lassen sich leicht ans der Einwirkung peripherer, einem vernünftigen Zusammenhang widerstrebender Erregungen verstehen.

\section{Desorientirtheit und Wahnbildung.}

Wie kommt nun auch in Zeiten nicht so hochgradiger Excitation die Desorientirtheit, welche sich gewöhnlich bei den ausgesprochenen Fällen wenigstens zeitweise findet, zu Stande? Der Delirant verkennt Ort, Umgebung, Personen, er weiss häufig Tag und Stunde nicht richtig anzugeben.

Dass der Delirant, auch während er desorientirt ist, Gegenstände erkennt und richtig bezeichnet, habe ich oft erprobt. Ja sogar angestellte Leseversuche zeigen, das viele Worte richtig gelesen werden. Bei einzelnen verliest sich der Delirant, so liest er statt "VerhandIung", „Verwandlung", statt „Rechtsstreit", „Rechtssache", statt „Zwangsvollstreckung", "Lwangsentsetzung". Op ...... verfehlte so ziemlich constant je das zehnte Wort. Andere schon das dritte oder vierte. Also sie ersetzten nicht percipirte Theile durch Ergänzungen aus der Erinnerung, erhalten aber, wenn sie aufmerken, genügend scharfe Netzhantbilder.

Kurzum: Der Delirant sieht deutlich, wenn er aufmerkt, er versteht auch dann, was er sieht. Aber er merkt freiwillig nicht auf, andauernd nicht einmal auf Aufforderung. Dem entspricht das häufige schon erwähnte Sichverhören des Deliranten.

Die Unzulänglichkeit in der Wahrnehmung des Deliranten kam schon bei Abhandlung der Illusionen zur Sprache. Der dort beschriebene Versuch (Zeitablesen von der Uhr) sagte dasselbe: Ausreichende Sehschärfe, aber nicht genügende Sammlung von Netzhautbildern und sonstigen Daten, die zur Construction eines Gegenstandes erforderlich sind, weil die dazu nöthige A afmerksamkeit fehlt.

Statt also bedächtig Aussenweltseindrücke aufzunehmen und sie zu dem Situationsbilde zu combiniren, appercipirt er im besten Falle vereinzelte Eindrücke und ergänzt sie leichtfertig aus seinem eigenen Innern.

Diese Unfähigkeit aufzumerken ist gewiss schon primär; gesteigert wird sie nun auf's höchste durch das Auftreten von Eigenproducten. Kommen nämlich dazu Hallucinationen, so treten diese in den Blickpunkt der überhaupt noch erreichbaren Aufmerksamkeit, die Wirklichkeit bleibt ein Chaos von verschwommenen Eindrücken, auf welche die Psyche gewissermassen nicht "eingestellt" ist. 
Ist es da verwunderlich, wenn der Kranke durch solche Eindrücke nicht an der Festhaltung einer Situation behindert wird, für welche er durch Sinnestäuschungen oder dadurch, dass sie ihm die gewohnte alltägliche ist, voreingenommen ist?

Dazu, dass der Delirant sich bei der gewohnten Beschäftigung: dünke, wird gar nicht einmal eine abundante Production von Sinnestäuschungen nothwendig sein. Der eingeübte Mechanismus, die festgewordene Associationsreihe wird von selbst ablaufen, wenn nur die äusseren Eindrücke nicht hemmend eingreifen. Letzteres ist aber, wie wir sahen, nicht der Fall. Die einmal gewonnene Ueberzeugung ist immer bereit, die nebelhaft zuströmenden Eindrücke in ihrem Sinne zu assimiliren.

So kommt der "Beschäftigungswahn" der Deliranten zu Stande. Er fand sich in $1 / 4$ unserer Fälle. Der Schlächter schlachtet, der Schneider näht, der Kellner will Bier austragen u. s. w.

Selbst wenn neben Sinnestäuschungen eine verhältnissmässig klare Auffassung der Wirklichkeit besteht, bedingen erstere eine Verzerrung des Situationsbildes. Ein delirirender Pneumoniker hatte, im Kastenbett liegend, die elementare Täuschung, er fahre, erkannte aber daneben, dass er und die Nachbaren in Betten lagen. Dies combinirte er zu der Meinung, er fahre im Krankenwagen der Staatsbahn.

Da eine richtige zeitliche Orientirung an die regelrechte innerliche Registrirung der die Zeit erfüllenden objectiven Vorgänge gebunden ist, so kann sie beim Deliranten schon in Folge des Fehlens dieser Registrirung nicht zu Stande kommen. Er spricht von dem, was vor einigen Stunden geschah, als von "neulich" Geschehenem, weiss nicht, wie lange er in der Anstalt ist u. s. w.

Eine unzweifelhafte Urtheilsschwäche begünstigt die Anerkennung und absurde Combinirung der Trugwahrnehmungen. Sie geht schon aus der an mehreren Beispielen (vgl. S. 23) erläuterten Unterlassung der Correctur einer Sinneswahrnehmung durch die andere hervor. Sie erklärt auch, dass das Unmögliche für möglich gehalten, das Abenteuerlichste geglaubt wird.

Wir haben gesehen, wie Hallucinationen, Illusionen zusammen mit formalen Mängeln in der Wahrnehmungs- und Urtheilsbildung, wahnhafte Ueberzeugangen beim Deliranten erzeugen, insbesondere Verkennung der Situation, der Person u. s. w. Die Tänschungen, selbst die des Urtheils, waren immer solche, welche dem Kranken eine verkehrte sinnliche Welt vorspiegelten.

Es fragt sich nun, ob auch auf anderem Wege entstandene Wahnideen bein Delirium tremens vorkommen. Ob also bei intacter Erkennung der Sinnenwelt blosses Verkennen der Kausalzusammen 
hänge, Missdeatung von menschlichen Gesinnungen und Absichten u. s. w. zu Wahnvorstellungen führe. Unsere Fälle jedenfalls sprechen nicht dafür. *) Unsere Deliranten hatten die verschiedenartigsten Wahnideen. Aber immer, wenn man ihreHerkunft verfolgte, ergab sich, dass sie auf bestimmte vermeintliche sinnliche Erlebnisse während des Deliriums zurückführten.

Ein Delirant verweigerte mit dem Zeichen höchsten Abscheu's Fleischnahrung. Es schien zuerst, als ob es sich um eine primäre Wahnidee handle. Als er etwas klarer geworden, gab er mir an, er habe auf dem Wege nach der Zelle ans Kinderleichen Würste herstellen sehen, habe haher die Meinung bekommen, in der Charité werde überhaupt Menschenfleisch verabreicht.

Nicht selten findet man einen Deliranten, der frei von Hallucinationen ist, über die Umgebung wohl orientirt ist, nur eine ziemlich isolirte Wahnidee äussert. Aber auch hier fand ich regelmässig bei näherer Nachforschung, dass diese Idee ihren Inhalt einem Erlebniss entnimmt, das der Delirant in einem vorhergegangenen Stadium der Hallucinationen und Illusionen gehabt hat. Der Glaube an bestimmte hallucinirte Vorgänge kann tage- ja wochenlang den Abschnitt der eigentlichen Wahnproduction überdauern. Solche persistirende Idee sitzt dann wie ein Fremdkörper in der sonst schon annähernd gesunden Psyche. Annähernd - denn die Kritiklosigkeit, mit der eine solche oft allen Mäglichkeiten widerstreitende Idee festgehalten wird, ist ja ein Beweis noch vorhandener Störung.

Thom..... hielt zehn Tage lang nach Aufhören der Sinnesdelirien daran fest, sein Kind sei todt. Als die Frau ihm, um den Wahn zu beseitigen, das lebende Kind mitbrachte, gab er seine Idee nicht etwa auf, sondern meinte: "Dann ist es eben wieder auferstanden". "Ich habe es ja selbst sterben gesehen". Schon den Tag vorher habe eine Frau Minkwitz ihm gesagt: "Das Kind macht nicht mehr lange". Richtig habe er es bald ganz still im Bett liegen gesehen. Die Füsse hätten sich eisig angefühlt. Er war auch beim Begräbniss zugegen, welches 19 Mark gekostet habe.

Aehnlich persistirte bei einem im Uebrigen recht vernünftigen Manne, trotz aller Gegenvorstellungen über eine Woche lang, die Meinung, ein ihm befreundeter Cigarrenhändler habe sich vor seinen Augen im Zimmer in eine Taube rerwandelt, sei auf das gegenüberliegende Dach geflogen und habe ron dort aus auf ihn geschimpft. Zum Beweise führte er eine Menge Augenzeugen an.

*) Ich spreche nur von dem acuten Delirium tremens, nicht von anderen alkoholistisehen Psychosen. 
Sch... hielt lange daran fest, dass Nachts sein ganzes Haus mit Bewohnern auf einen Kremser geladen worden sei. Derselbe sei damn in den Grunewald gefahren, wo man ihn rom Bock geschmissen habe, "dass das Feuer aus den Augen sprang"t.

Wo solche Idee besteht mit ihren Consequenzen, bei zur Zeit völligem Fehlen von Delirien, kommt die "systematisirende" Form Jolly's*) zu Stande, die der im engeren Sinne delirirenden Varietăt gegenübersteht. Ihren Ursprung nahm aber in den von mir beobachteten Fällen diese Idee stets einem vorangegangenen Stadium der Sinnesdelirien. Dementsprechend bezieht sich der Wahn der Deliranten auch stets anf concrete Vorgänge nGeschichten" und zwar solche, die in der Gegenwart oder unmittelbaren Vergangenheit, also während des Deliriums sich abgespielt haben. Nie ging er auf die fernere Vergangenheit, Kindheit u. s. w., nie auf den Charakter der eigenen Persönlichkeit, dauernde soziale Verhältnisse, allgemeine, nicht concrete Punkte, stets war vielmehr sein Inhalt: "Das und das habe ich erlebt" nebst den einfachsten Folgerungen daraus.

Insbesondere beachtenswerth ist, dass bei keinem der 125 Falle, die meiner Beobachtung unterlagen, eine Alterirung des Ichbewusstseins aufgetreten war. Alle Deliranten, mochten sie noch so desorientirt über die Aussenwelt sein, sich in lebhaftester Production von Hallucinationen und Wahnideen befinden, waren sich über ihr eigenes Ich durch. ans im Klaren. Nie glaubte einer von ihnen wie ein Paranoiker oder Paralytiker etwa Gott, König, Thier u. s. w. 嗼 sein. Der aufgeregteste Delirant weiss, dass er der Arbeiter So und so, oder der Kutscher So und so jst. Weder in expansivem noch depressivem Sinne giebt er sich Täuschungen über seine Person hin. Während gerade der Vorstellungscomplex, der die Bedeutung der eignen Person und was damit fest verwachsen ist: die Stellung in der Gesellschaft, die tägliche Beschäftigung, die gewohnte Umgebung betrifft, beim Paranoiker und Paralytiker häufig zurückgedrängt ist durch neu eingenistete Ueberzeugungen, ist er beim Deliranten hinübergerettet in die sonstige geistige Umnachtung. Ja er wird oft geradezn in krankhafter Weise den veränderten Verhältnissen gegenüber festgehalten. Wir hatten gesehen, dass der Delirant häufig noch dem vertrauten Beruf obzuliegen, in seiner täglichen Umgebung zu sein glaubt, wenn er sich bettlägerig im Krankenhaus befindet.

*) Allg. Zeitschr. für Psychiatrie Bd. 51. 1894. Heft 1. S. 193, Bericht über die 80. Vers. des psych. Vereins in Berlin, in der Diskuss. über Paranoia. 
In diesen Fällen besteht also ein Hauptsymptom des Deliriums gerade darin, dass die mit dem Ichcomplex fest verwachsenen Vorstellungen der Ablösung durch die von dem veränderten Milieu geforderten Vorstellungen widerstehen.

In den übrigen Fällen wird, wie gesagt, wenigstens das Ich der Vergangenheit festgehalten. Daran ändert Nichts, dass in dem Wahn des Patienten Allerlei an seinem Ich vorgehen kann. Delirant 0 p... und Delirantin Rie... glaubten, sie seien gestorben. Aber die, welche gestorben waren, das Subject, waren eben sie: der $0 p \ldots \ldots$ beziehungswoise die $\mathrm{Rie} . .$.

Kurzum Alles, was etwa während des Deliriums mit dem Deliranten (in seiner Meinung) vorgeht, geht an der durch das ganze vorangegangene Leben aufgebauten Persönlichkeit des Deliranten vor sich. Diese selbst wird festgehalten.

Fassen wir kurz zusammen, was die Beobachtung der spontanen Delirien ergeben hat:

Der vorherrschende Affekt im Delirium tremens ist die Angst, und zwar ist ihr primärer Charakter wahrscheinlich.

Sie führt nicht zur Selbstbezichtigung, sondern zu Handlungen der Selbsterhaltung.

Die vorstellende Seite der Psyche betreffend liessen sich zunächst in über der Hälfte der darauf geprüften Fälle eine Reihe elementarer Sinnesanomalien beobachten, welche schon vor Ausbruch des eigentlichen Delirium's begonnen hatten und während desselben in freieren Zeiten fortbestanden.

Unter den complicirten Sinnestäuschungen überwog die Illasion. Entfernung, undeutliche Form der Gegenstände, kurz Alles, was ein unscharfes Netzhautbild bedingt, zeigte sich als illusionsbegünstigend. Eine von vornherein unzureichende Abbildung der Dinge auf der Netzhaut in Folge herabgesetzter Sehschärfe liess sich nicht als wesentlicher Grund für die illusorische Entstellung des Gesehenen nachweisen. Vielmehr zeigte sich der Mangel der Aufmerksamkeit, mit der die zur Erkemnung eines Gegenstandes erforderlichen Akte vorgenommen wurden, als Hauptursache. An Stelle der nicht percipirten Ausseneindrücke traten dann fälschende Zuthaten aus dem Innern.

Inhaltlich überwiegt unter dem Wahrgenommenen Schreckliches. Thiervisionen kamen bei 70 pCt. zur Kenntniss.

Das Gesehene stellt theils unverknüpfte Wandelbilder, theils zusammenhängende Erlebnisse dar. 
Es ist körperlich, farbig, nach anssen lokalisirt.

Gehörstäuschungen wurden bei $40 \mathrm{pCt}$. beobachtet, und dann be sonders bei denen, welche in hallucinationsfreien Zeiten an subjectiven Gehörsempfindungen gelitten hatten. Wenn überhaupt, kamen sie gehäuft bei demselben Deliranten vor.

Die Mehrzahl, 60 pCt., schilderte ihre Erlebnisse nur von der sichtbaren Seite.

Die Deliranten zerfallen danach in eine Mehrheit von Visionären und eine Minderheit von Visionär-Aưditionären.

Bezüglich der Auffassung des Wahrgenommenen liessen sich folgende Stufen unterscheiden:

1. Es wird unmittelbar als Täuschung erkannt.

2. Es wird mittelbar als Täuschung erkannt.

3. Es wird für real, aber für "Spiel" gehalten.

4. Es hat volle Realität.

Die zusamnuenhängenden Erlebnisse waren der MehrzahI nach Wacherlebnisse.

Es gehen in dieselben ausser Sinnestäuschungen noch Urtheilstäuschungen ein. "Phantasmen" in Rose's Sinne liessen sich nicht ermitteln.

Die Unfähigkeit, die Aufmerksamkeit anzuspannen, zusammen mit den Sinnestäuschungen zeigte sich als Hemmniss für die Gewinnung eines richtigen Situationsbildes. Die so durch berichtigende Aussenwelteindrücke nicht behinderte Fortspinnung der gewohnten Vorstellungsreihen und eventuell unterstützende Sinnestäuschungen ergaben den Beschäftigungswahn.

Urtheilsschwäche erklärte, dass das Unmögliche und Absurde unberichtigt bleibt. Die sonstigen Wahnideen führten stets auf die durch die vorerwähnten Faktoren zu Stande kommende Verfälschung der Sinnenwelt zurück. Was auf Grund der Sinnestäuschungen und der unmittelbar sich anschliessenden Urtheilstäuschungen von sinnfälligen Ereignissen dem Kranken vorgespiegelt wird, giebt den Inhalt seines Wahnes ab. Derselbe ging daher stets anf Ereignisse, und zwar solche, welche sich während des Deliriums abgespielt hatten. Primäre Wahnideen, solche, die auf Unsinnliches, Längstvergangenes, insbesondere auf den Charakter der eigenen Persönlichkeit gerichtet gewesen wären, kamen nicht vor.

Ich gehe nunmehr zur Mittheilung der mehrfach erwähnten Versuche, die künstliche Auslösung von Visionen bezweckend, über. Sie gingen aus einer bestimmten Fragestellung hervor, lehrten mich aber 
dann, ganz abgesehen von ibrer Qualification zur Beantwortung dieser Frage, eine Methode kennen, welche über das Innenleben des Deliranten viel zuverlässigere Aufschlüsse gewinnen lässt, als es bei der einfachen Beobachtung der spontanen Delirien möglich ist. Der Beschreibung der Methode, der Schilderung der mit ihr gewonnenen Ergebnisse mögen die einfachen Erwägungen, welche zu ihrer Anwendung führten, vorangehen.

\section{Künstlich ausgelöste Simestäuschungen: Druckvisionen.}

Die Betheiligung peripherer Sinnesreize an dem Zustandekommen von Trugwahrnehmungen ist für zahlreiche Fälle bei Hallucinanten verschiedenster Art wahrscheinlich gemacht worden.

Schon auf die normal vorhandenen entoptischen und entotischen Reize hat man als derartige Erreger hingewiesen. Sie entgehen für gewöhnlich dem Bewusstsein, werden aber bei gesteigerter Aufmerksamkeit, im Affect und unter anderen besonderen Bedingungen bemerkt. Purkinje, Hoppe und Andere haben besonders für das Gesicht diese entorganisch bedingten Empfindungen beschrieben.

Noch einleuchtender ist aber die Hallucinationen auslösende Wirksamkeit peripherer Reize für pathologische, abnorme Erregungen dieser Art erwiesen worden.

Gefühlshallucinationen sollen aufgetreten sein bei Hornhaut-, Linsen-, Glaskörpertrübungen, bei Neuritis optica. Gehörshallucinationen bei Paukenhöhlenkatarrhen. Interessant ist der Fall von Prof. Naegeli. Derselbe beobachtete an sich selbst nach Verbrennung seiner Hornhaut mit kochendem Spiritus, Visionen von Landschaften, Gegenständen a. s. w. Eine wirkliche Abbängigkeit der Sinnestäuschung von der Organerkrankung liess sich besonders in den Fällen stricte nachweisen, in denen beide ein- und gleichseitig auftraten, oder nach Entfernung des Organs die Täuschungen verschwanden oder dieselben aus anfänglich blossen sogen. subjectiven Empfindungen sich entwickelten und bei eintretender Genesung sich zu diesen zurückbildeten.

Solche isubjectiven Empfindungen" d. h. Funken- und Farbensehen, Flimmern, beziehungsweise Ohren-Sausen und -Klingen hat der psychisch Gesunde bei gleichen Reizen. Die im obigen Sinne aufgefassten Hallucinationen wären also die Aequivalente der „subjectiven Empindungen" des Gesunden beim Geisteskranken.

Eine weitere Reihe hierher gehöriger Erfahrungen liegt äusseren Eingriffen gegenüber vor. 
$J_{\left.011 y^{*}\right)}$ gewahrte, gelegentlich seiner Untersuchungen über die Erregbarkeit des Acusticus bei Geisteskranken, anf elektrische Reizung neben Hyperästhesie und der sogen. paradoxen Reaction als interessanten Nebenbefund das Auftreten von Gehörshallucinationen. Es wurden einzelne Worte und ganze Sätze wie: "den Kaiser habe ich umgebracht, jetzt geht der Schleim herunter" u. s. w. gehört. Da die Hallucinationen nicht nur bei Anodenöffnung und Kathodenschliessung auftraten, sondern überhaupt bei jeder derart gesteigerten Stromstärke, dass Schmerz empfunden wurde, gleichgiltig ob-in dieser order jener Richtung geöffnet oder geschlossen wurde, entschied sich J. dafür, dass es sich nicht um elektrische Reizung des Acusticus sondern des sensiblen Trigeminus und reflectorische Uebertragung auf die Centren des Acusticus handele. Köppe $\mathrm{e}^{* s}$ ) fand Gehörshallucinationen auftreten bei Einführen eines Trichters in das $\mathrm{Ohr}$ und ähnlichen Manipulationen.

Nun liegt aber hier eine Frage vor, zu deren Beantwortung wir nicht auf zufällige Befunde, auf gelegentliche Coincidenzen zwischen anatomisch nachweisbarer Erkrankung des Sinnesorganes und Sinnestäuschungen angewiesen sind, die vielmehr experimenteller Prüfung zugänglich ist. Da wir im Stande sind, inadäquate Reize der Sinnesorgane künstlich zu erzeugen, so ist uns hier der überall sicherere und ausgiebigere Resultate verbürgende Weg: des Versuches geöffnet.

Speciell für die Alkoholdeliranten war auf die Möglichkeit, dass auch bei ihnen alle oder ein Theil der Hallucinationen von peripheren Reizen ausgehen, schon von mehreren Seiten hingewiesen worden. So schreibt $\mathrm{Näcke} \mathrm{F}^{* * *}$ ) in seiner Bearbeitung des Delirium tremens (S. 450): "Aber auch die Entstehung von Illusionen durch eine Lichterscheinung auf entoptischem Wege ist denkbar; von jenen durch die noch fragliche Hyperämie der Retina bedingten Funken, feurigen Kugeln etc. abgesehen, kann nämlich leicht der Fall eintreten, dass einmal der Bulbus direct mit der Bettkante in Berührung kommt und so eine starke Lichterscheinung peripher erzeugt und im Gehirn weiter verarbeitet wird."

Dass der Zustand des Sinnesorganes ganz allgemein auf die Täuschungen einen Einfluss übt, nimmt auch Mendel an, wenn er schreibt: „Die Form der Gesichtshallucinationen steht im Delirium tremens wohl

*) Beitr. zur Theorie der Hallucination. Areh. f. Psychiat. IV. 1874.

**) Gehörsstörungen u. Psychose. Allg. Zeitschr. f. Psych. XXIV. ***;) 1. c. 
im Zusammenhang mit den Störungen der Accommodation und Verändernngen im Augenhintergrund".*)

Es fragt sich nun: ist jene Denkbarkeit Näcke's eine Wirklichkeit? Wenn alle oder nur ein Theil der Hallucinationen der delirirenden Säufer von entorganischen Erregungen ausgehen, so muss umgekehrt artificielle Herstellung solcher Erregungen Hallucinationen auslösen.

Zur Entscheidung der Frage bot sich als einfachste und unschädlichste Erregung der blosse anhaltende Druck auf den Augapfel.

Die Wirkung eines mässigen Druckes auf das Auge eines Gesunden kann jeder an sich selbst erproben. Finden auch individuelle $A b$ weichungen statt, und bedingen auch Art des Druckes und der Umstände Variationen, so zeigen doch die Angaben verschiedener Personen im wesentlichen übereinstimmende Charaktere der "Druckfigur", des sogen. Phosphens. Es ist übrigens durchaus nicht nöthig, dass das Auge geschlossen wird. Bei offenen Angen entsteht dieselbe Lichtfigur. Dieser Punkt kommt später noch zur Besprechung. Purkinje $\mathrm{e}^{* * s_{5}}$ ) sah bei allmälig wachsendem Fingerdruck einen breiten hellen Ring, der in der Mitte eine kreisförmige dunkle Lücke zeigte. Bald wurde die Mitte hell, der Ring dunkel, um ihn folgte dann noch eine helle und wieder eine dunkle Zone. Dann trat eine 8 strahlige Figur auf, zwischen deren Strahlen sich eine Menge kleiner Vierecke ausbreitete. Drückte er gleich stark, so erschienen leuchtende Schlangenlinien, die im Wechsel von dunkel und hell durcheinanderspielten. Bei noch stärkerem Drucke hellleuchtende Punkte, bei Nachlassen Zacken und Aestchen.

Weniger gesshulte und sorgfältige Beobachter machen Angaben, die sich leicht als undeutlichere Auffassungen der von Purkinje beschriebenen und aufgezeichneten Erscheinungen erkennen lassen. Sie geben gewöhnlich an: Es wird hell, eine leuchtende Scheibe, wie die Sonne, ein bewegtes Lichtmuster, wie eine Tapete, Sterne, Schlangenlinien and Aehnliches. Immer sind es primitive Empfindungen, nicht Bilder von Objecten, höchstens wird einmal vergleichsweise ein solches herangezogen.

Die Voraussetzung nun, dass bei Deliranten an Stelle dieser primitiven Empfindungen complicirte Visionen auftreten würden, wurde durch die Versuche in grösstem Umfange bestätigt.

*) Eulenburg's Encyklopaedie Bd. V. S. 166.

**) Beabachtungen und Versuche zur Physiologie der Sinne. I. 1823, II. 1825 . 
Ich habe 52 Deliranten, bei denen spontan Sinnestäuschungen aufgetreten waren, daranf untersucht. Bei nur 12 misslang die künstliche Erzeugung von Visionen durch Druck.

In 40 Fällen ( $77 \mathrm{pCt}$.) wurden durch Druck anf die Augen Visionen erzengt, und zwar gelingt dies besonders während des eigentlichen Deliriums. Mit zunehmender Klarheit des Patienten nähern sich die Versuchsergebnisse immer mehr dem Negativen, bis bald nach dem vollen Ablauf des Deliriums der Genesene auf den Eingriff genau reagirt wie ein Gesunder. Bei den sogenannten Abortivdelirien fanden sich stets negative Resultate.

Die angewendete Methode ist ungemein einfach. Man forderte den Kranken auf, die Augen zu schliessen, nachdem man sein Vertrauen gewonnen und ihn zu behaglicher Mittheilsamkeit gebracht hatte. Hierauf wurden die Daumen auf die Lider gelegt und ein sanfter allmälig zunehmender, nöthigenfalls durch leichtes Reiben unterstützter Druck geübt. Ganz gleichwertig ist der Druck bei offenem Auge, er muss nur etwas stärker geübt werden. Suggessivfragen wurden grundsätzlich vermieden. Ich leitete das Gespräch gewöhnlich mit der Frage ein: "Ist es hell oder dunkel?" Meist bekam ich die Antwort: "Ganz duster", "dunkel", "ich sehe nichts", ,gar nichts". Bald aber folgt die Angabe: "Jetzt wird es heller", ,ganz hell", sehr häufig tritt nun aber schon die Angabe auf: „Jetzt geht die Sonne auf" oder "Sonne, Mond und Sterne", oder Patient schildert noch zunächst mehr oder minder phantasievoll Gebilde, denen man die Zugehörigkeit zur Purkinje'schen Druckfigur ansieht, die sich aber durch die phantasievolle Deutung schon von den Angaben der Gesunden leicht unterscheiden. So habe ich aus diesem ersten noch nicht den eigentlichen Höhepunkt der Reaction des Deliranten darstellenden Stadium folgende Angaben verzeichnet: ,Goldene Knöpfe, Wolken, Sonne, Schatten, Blitze, ein Stickmuster, goldene Pickel, rothe Tapete, Fragezeichen" u. s. w.

Auf dieses erste Stadium folgt das zweite, das der zusammengesetzten Visionen, welches im Folgenden näher za beschreiben ist. Bei sehr aufgeregten, hochgradig hallucinirenden Patienten fehlt das erste, es treten sofort complicirte Gesichtserscheinungen auf.

Man darf nur nicht sogleich vom Versuche abstehen, wenn der Patient mehrere Male erklärt hat, er sehe nichts oder wenn es zunächst nicht über die Primitivempfindungen hinauskommt. Oft gelingt es nicht sofort, die Aufmerksamkeit des Patienten zu fixiren oder er empfindet die Manipulation zuerst als lästig.

Ersteres ist namentlich bei sehr erregten und verwirrten Patienten der Fall. Umgekehrt glauben Halbklare sich durch Zugeständniss von 
Visionen zu discreditiren; es gilt daher hier noch mehr, wie bei den Uebrigen, durch Ruhe, möglichst harmlose Vornahme des Verfahrens, Vermeidung allen Aufhebens das Misstrauen des Kranken zu zerstrenen. Häufig erklärten solche Patienten wiederholt, sogar mit einem gewissen Trotz, es sei alles duster, sie sehen gar nichts und doch gelang es noch bei einiger Ausdauer sie zum lebhaftesten Halluciniren zu bringen.

Whe man daher ein negatives Resultat verzeichnet, muss man mit einer gewissen Geduld jenen Widerständen zu begegnen versucht haben. Oft ist ein Versuch, der hente gänzlich misslang, am folgenden Tage erfolgreich. Dem vorerwähnten Momente ist auch für die Beurtheilung der negativen Fälle Beachtung zu schenken. An Dissimulation ist zweifellos in einigen Fällen zu denken. Verdächtig derselben macht sich die Versuchsperson, wenn sie hartnäckig erklärt: „Nichts zu sehen“, also auch die doch sicher vorhandenen Primitivempfindungen in Abrede stellt. Auch trifft man wohl picht jederzeit die richtige Disposition.

Betreffs der Deutung der Ergebnisse wird eingehend zu sprechen sein. Zuerst empfiehlt es sich jedoch, die Beobachtungen selbst zur Mittheilung zu bringen. Nur in 2 Fällen wird man eine Fragestellung finden, der man eine suggestive Wirkung zuschreiben könnte (in dem einen Fall übrigens ohne Erfolg). Später machte ich mir zum Grundsatz, solche Fragen wie: „Sehen Sie Thiere?"6 u. dergl. zu vermeiden, ausser wo es darauf ankam, das Fehlen früher dagewesener Visionen nach dem Delirium zn sichern, wo also ein Inabredestellen trotz etwaiger Suggestivwirkung von erhöhter Beweiskraft war. Die Aufforderung: „Beschreiben Sie, was Sie sehen" ist oft nicht zu vermeiden.

Den nun folgenden Mittheilungen der Versuchsergebnisse sind bei einem Theil der Fälle kurze Angaben über das allgemeine Verhalten und namentlich die spontanen Sinnestäuschungen vorangeschickt, damit der Vergleich der spontanen mit den artificiellen Hallucinationen ausführbar ist.

Im Folgenden bedeutet: „uegativ" das Auftreten blosser Primitivempfindungen oder gar ein Sehen von "Nichts".

Wie noch besprochen werden wird, genügte bei einem Theil der Deliranten schon der blosse AugenschIuss (mit übergelegtem Tuch) um Visionen zu erzeugen. Wo solche Versuche gemacht worden sind, sind die Ergebnisse denen des Drucks vorausgeschickt. „Schluss“ bedeutet dann "AngenschIuss".

Ich beginne mit einer Gruppe von 18 Patienten (unter 40), welche die merkwürdige Eigenschaft gemeinsam hatten, die in dieser Häufigkeit sicher'nicht zufällig sein kann, bei Druck auf die Augen: Geschriebenes oder Gedrucktes zu sehen. Sie lesen es eatweder fliessend 
ab oder entziffern es mühsam. Bald sind es sinnvolle Worte und Sätze, bald bedeutungslose Silbenaggregate, bald Zahlen und einzelne Buchstaben. Und zwar wiederholt sich dieses Phänomen bei verschiedenen Versuchen an derselben Person. Ein Theil der Personen sah daneben noch Anderes.

\section{Versuchsprotokolle*).}

1. W. befindet sich am 19. Juni im vollen Delirium, hält Flecke im Bett für Wanzen, greift nach ihnen, lässt sich eine Spinne suggeriren.

Bei Druck auf die geschlossenen Augen sieht er: goldene Knöpfe, Seide, 2 Häuser.

Nun beginnnt er zu lesen: „Diskontogesellschaft, Richard Freund, Werner, Offenbach, Hutmacher und Corsetfabrik" u. s. w.

Auf die Frage: "Wo sehen Sie das?" zeigt er an die Decke.

"Wie sehen Sie das?" Er: „In Chocoladenschrift". "Sehen Sie keine Thî̉ere? (Erst später habe ich den Grundsatz befolgt, nie solche Fragen zu stellen). "Jetzt sehe ich gar nichts". „Und jetzt? (bei leichtem Reiben) "Acht Pudels" (er lacht) "Da kommt noch einer und ein Ponny den Berg herauf. Nach Oeffnen der Augen sieht er dann noch einen Augenblick "Pudels und Ponny's". angemalt"t.

"Wie kommen denn die her nach der Charité?" „Die hat gewiss Jemand

Am nächsten Tage glaubt Patient, der in einem Kastenbett liegt, Omnibus zu fahren. Er sieht seine Frau, bellagt sich, er und seine Frau seien von 16 Mann durchgeprügelt worden.

Bei Druck liest er sofort: "Ingwerfabrik, Sectionshans, Rossfett u. s. w." "Wie sehen Sie das?" In 6 Zoll grossen Buchstaben". Dann sieht er Barsche und Dorsche.

Nach Oeffnen erklärt er, auf Befragung: „Das Glas vergrösserte sehr gut, die Buchstaben sind sehr gross gewesen", hatte also die Vorstellung, man habeibn durch ein Vergrösserungsglas sehen lassen!

Am nächsten Morgen schläft Patient ein und schläft den halben Tag. Nach Erwachen ist er orientirt. "Wo sind Sie?" „Im Bett". „In welchem Hause?" "In der Charité".

Bei Druck auf die geschlossenen Augen bleibter viel ruhiger, als an den vorhergehenden Tagen, an welchen sich seine Mittheilungen über das Gesehene, sofort und wie explosiv entluden. Erst sieht er "Nichts", dann: „Es winkt Jemand"6. "Wo?"6 "Das kann ich nicht sehen, jetzt zerreisst er was". „Ein Mann oder eine Frau?" „Das kann ich nicht sehen, jetzt steht ein Korb und eine Kiste da - jetzt sind sie weg"t. Man bemerkt, wie viel unbestimmter und blasser an diesem Tage die Erscheinungen auftraten.

*) Die bei Beginn des Versuches auftretenden Angaben, dass Sonne, Mond, Sterne u. s. w. gesehen würden, sind nicht immer mit verzeichnot, 
Patient schläft nun Tag und Nacht. Erzählt nachher ,er träume Alles durcheinander". Ein nun wieder unternommener Druckversuch verlief völlig negativ. Patient erklärt, „er sehe gar nichts“". Er ist völlig lklar über die Gegenwart, glaubt aber noch an die Realität des früher spontan Gesehenen. Er erinnert sich seiner Druckvisionen genau. Er giebt an, er habe Schilder an Häusern gesehen, die mit Firmen bedruckt waren. Die Buchstaben waren zum Theil riesengross. Er meint jetzt, es sei Alles Einbildung gewesen "damals habe ich aber fest daran geglaubt". Speciell erinnert er sich, das Schild der Corsetfabrik von Mannheimer gesehen zu haben. „Haben Sie die öfter früher gesehen?" "Gewiss, die ist ja auf dem Gendarmenmarkt, da sind wir ja auch mit dem Omnibus vorbeigefahren". "Die Thiere sind vom Berg heruntergekommen".

Betrachten wir das zeitliche Verhältniss der artificiellen zu den spontanen Visionen, so ergiebt sich, dass einige Stunden nach A ufhören der letzteren sich erstere noch erzeugen liessen, aber in abgeschwächtem Grade, dass sie aber nach wieder 18 Stunden ebenfalls wegblieben.

2. Ein zweiter Fall dieser Art war Fr...

26. März. Liegt unruhig im Bett, ist nur halborientirt, aber zur Zeit frei von Sinnestäuschungen, nur glaubt er "Alles fliege".

Druck: Er liest: „Theaterstrasse, Gangolfhofenstrasse, $r$, t, u“. Nach Aufhören des Druckes liest er einige Zeit weiter.

BeiVerstopfender Ohren hörter Ticken und Schlagen der Uhr.

27. März. Patient hat traumlos geschlafen. Ist klar ïber die Gegenwart, hält alles Frühere aufrecht. Heute Druck wirkungslos $=0$.

3. Franz Schm ...

Ueber Ort und Zeit orientirt, jetzt frei von spontanen Sinnestäuschungen.

Druck: Nichts, Zahlen 33, 56 etc. "Helle Zahlen im Dunkeln“.

Bei wiederholtem Druck wieder Zahlen.

31. März. Ist heute ganz klar. Druck völlig negativ. Erinnert sich, gestern die Zahlen hell auf dunklem Grunde gesehen zu haben, wie auf "Lottomarken". „Es zeigte sich ein heller Kreis wie ein Pfennig gross und da standen die Zahlen dran. Es war ganz deutlich etwa $1 / 8$ Mtr. weit.

4. W. . . 6. August. Patient ist desorientirt sieht massenhaft "Thiere und Pennbrüder". Spielt mit einem Hasen im Bett. „Komm, mein Häseken, komm". . .

Druck: Erst „dunkel, hell, Sonne, Kreise", dann "die Ecke, Häuser" (buchstabirend). "Gasthaus, Köpernick". "Wo steht das? "Auf dem Schild". "Jetzt fährt ein Möbelwagen mit zwei Pferden vorbei“. Fährt fort zu entziffern: „Packetfahrt, Köp--nik, nein, Kö-thener - das Uebrige kann ich nicht Iesen".

Nach Oeffnung der Augen sieht er noch eine Zeit lang das Gasthaus und versucht zu lesen.

Eine halbe Stunde später auf Druck: „Sargfabrik“. Befragt, giebt er an: "Die Buchstaben sind über zollgross". "Welche Farbe?" "Das kann ich nicht 
sehen. Da fährt ein Wagen. At-zak Ilï - nein Ulti . .." Nach Aufhören des Druckes liest er noch von einem Schild ab: "Bildhauer Vogel". Nachher auch bei offenen Augen: Hitzbock, Holz-lro-Gä-dik.

Nachts sehr erregt, sieht ein Thier, das ihn beissen will, flieht davor, wird isolirt.

7. August. Erzählt, er sei in der "Gummizelle" gewesen, habe dort einen Budiker gesehen, ebenso Hunde, Schlangen, Mäuse. Er weiss jetzt, wo er ist, sagt selbst; er habe „Manches zusammenphantasirt", ist noch unruhig, aber. hallucinirt nicht mehr.

Druck: „Der Himmel, manchmal regnet's. - Jetzt sehe ich Schriften. Ich kann sie aber nicht lesen". „Am Himmel?" "Ja hell wie gedruckt, es ist aber zu weit, ich kann es nicht lesen". "Sehen Sie Menschen?" (Lachend) "Ne, Menschen sehe ich nicht".

8. August. Patient ist heute klar.

Druck: "Dunkel, blaue und gelbe Streifen, ganz blaue Pünktchen". "Keine Schrift?" "Nein, keine Schrift". "Jetzt als ob Gold umherflöge". Als o nur Elementarempfindungen. Er erinnert sich gestern am blauen Himmel gelbe Buchstaben gelesen zu haben. Einen Theil habe er nicht lesen kömnen.

5. Schw... Nach Pneumonie gänzlich desorientirt. Erzählt grosses traumartiges Erlebniss, im Kremser.

Dr uck: Einige Zeit nichts, fängt dann an zu buchstabiren: Ore mi etc.

Bei einem zweiten Versuch $1 / 2$ Stunde später: "Sozialdemolratische Buchstaben, Hirsch u. Co., Hundert und zwanzig, Sinsen, sensi, 20". "Wie gross sind die Buchstaben?" "Der Satz ist11/2 Zoll gross", schwarz, 9 Zoll entfernt. Nach Oeffnen: "Was meinten Sie mit sozialdemokratischen Buchstaben?" „Ich kann es nicht anders ausdrücken".

10. September. Ist klar, hat schon zwei Nächte geschlafen, weiss seit gestern, dass er phantasirt hat.

Auf Druck: Rosa, grüngrau, Flimmern, Punkte wie marmorint. Also Elementarempfindungen.

11. September. Erinnert er sich, Schrift bei Augendruck gesehen zu haben. $1 \mathrm{Ctm}$. grosse schwarze Buchstaben. Es war gedruckt in lateinischer Art. In 12 Zoll Entfernung. „Wussten Sie, dass die Augen geschlossen waren?" "Nein, ich war ja im Fieberwahn". "Wissen Sie noch, wie Sie die Buchstaben nannten?" "Ja, sozialistisch". "Was meinten Sie damit?" „Damit meinte ich den Inhalt".

6. Wilhelm Mü... 20. September. Hat zu Hause "Männekens" gesehen. Ist orientirt, aber benommen.

Druck: „Es wird hell, Punkte, ein Buchstabe, jetzt ist er umgekehrt, jetzt wird eine Verzierung daraus". „Wie gross war der Buchstabe?" „Fingergross". Jetzt solche verschlungene Schlange. Jetzt wieder ein Buchstabe. "Welcher?" "Das soll wohl ein K. oder ein M. sein? Jetzt was Gravirtes". "Können Sie es lesen?" "Nein, es soll wohl ein R. sein?" "Wie sieht es aus?" "Wie mit Kreide geschrieben", 
Nach Oeffnen: „Wo kommen die Buchstaben her?" „Die haben Sie mit dem Finger gemacht".

21. September. Patient hat Nachts in dem Eisengeschäft arbeiten gesehen, angeblich im Schlaf. Puls 90.

Er hat offenbar noch Hallucinationen, wie aus seinen Bewegungen ersichtlich, stellt sie aber in Abrede.

Druck: „Ein längliches Ding mit einem Stern oben, jetzt eine Zahl: 4872, - weiss auf schwarzem Grunde, jetzt ist sie weg, soll das ein g oder ein h sein?. Jetzt ganz oben eine 4, rechts unten eine 3 und in der Mitte eine 2. Jetzt dreht sich die 2 um. Die Zahlen über fingergross, einen Meter weit. Zuletzt schwarz auf weissem Grunde".

Später lasse ich bei bloss geschlossenem Auge beschreiben, was er sieht. Er gieht dabei auch eine umgekehrte 8 an.

22. September. Ist höchst agitirt. Ganz desorientirt, spricht ron Schlosserei. Er ist dann wieder in der neuen Charité, „wo er das Familienvergnügen abhält". ,Das wird von der Firma gegeben".

Druck: (Sofort) „A, F mit einem T ein U. 51/10" (liest weiter Buchstaben und Zahlen), dann: "Langzoll".

Nach Deffnen der Augen sieht er nichts Derartiges, leugnet aucli, eben Zahlen gesehen zu haben.

Bei erneutem Schluss und Druck: „18749" u. s. w.

Dasselbe Ergebniss hatte ein 10 Minuten später wiederholter Versuch. Die Buchstaben wurden über fingergross angegeben, einmal, "wie im Buch", schwarz auf weiss, später grün auf grav.

7. Bi....... (Asthen.). 1. Sonne, Mond, Sterne, ein L ein W Trompete.

2. A jetzt B (leiert dann das A, B, C herunter). Sah auch bei offenen Augen Allerlei.

8. Fleí .... 28. Septembei: Druck: Böcke übereinander, Tisch, Korb mit Zahien: $64,3^{3} / 4$.

"Lesen Sie doch weiter!" "Ja, dann muss ich den Kopf mehr wenden". „Nun?" "Jetzt sind sie undeutlich - ein A, ein M, 64 .

29. September. „Rosa und Weiss. A, T, V 6 Zoll ab, 2 Zoll gross, schwarz auf roth) dann liest ex: „Herzogthum, Komm-batt". Nach Oeffnen sieht er den Boden roth.

Bei geschlossenen Augen ohne Druck sieht er auch Bäume, „aber nicht persönlich".

9. E ... 2. October. Druck 1: gleich 0 .

Druck: 2. Groschen, Zahlen 160, 23 etc.

3. October. Druck 1: Hört Summen und Singen, danm "Nichts". Schliesslich liest er: "Weidendammer Brüeke, Holzdorfstrasse" ete. (Buchstaben schwarz auf weiss, zollgross).

Druck 2: Ein Pferd, Wagen mit Pferden, elektrische Lampen.

10. K..... 8. März (Del.). Gar nichts.

9. März. Nichts, Ihr Hörohr, blaue Blumen (ich hatte ihn vorher auscultirt) nichts. 
10. März. Gelbe und hellblaue Punkte, sonst nichts.

12. März. Nach längerem Drücken: Ihr Gesicht, meinen Vorderfuss, eine Mühle.

13. März. Polizisten, Fuhrwerke, Guirlanden.

16. März. Blumen im Korb, blaugrün, Veilchen. „Sehen Sie denn nicht Buchstaben?"*) "R ... Ehre" (Letztes lesend).

17. März. Besen, ein Stuhl (erst nach längerem Drücken).

21. März. Gleich 0.

24. Juli. Exitus.

Patient hatte während der ganzen Zeit asthenische mussitirende Delirien, lag im Kastenbett, wurde zuletzt immer schwächer und starb an Dekubitus.

11. B... Versuch 1. Bei blossem Augenschluss: Häuser, goldene Buchstaben, Wasser, es regnet.

Bei Druck: Lichter, Himmel mit Streifen, Caros, darauf fängt er an zu lesen: "Sehen Sie Schriften?" "Ja". "In welcher Farbe?". "Alles blauschwarz".

Versuch 2. Bei Schluss: Preussen, dann Unverständliches. „Buchstaben". "Wie gross?" ,3-5 Mm." Der Hintergrund Quadratsteine. Viele Vögel fliegen vor dem Hause. In der vorgenannten Strasse befindet sich eine Mosaikplatte, grosse und kleine, Masse Teller (liest) „Gab uns Faden, Vasen so und so". Giebt dann an "die grossen Buchstaben waren 1500-2000 Metel weit, durch das Glas gesehen".

Bei Druck: Gestalten, dodig, männlich und weiblich, menschliche Gestalten. „Schriften, Zinsdruck No. 22"4, schöne Schlipse rerschiedene Farben, zum Schieben, Klappen und Stehen.

Bild mit zwei Wagen, (liest) „Dienstinstitut" (15-16 Ctm. und grösser 25-30 Ctm.), Farbe dunkel, Hintergrund blan.

12. B ..... Bei Schluss: constant ,Nichts".

Bei Druck von oben: lange „Nichts". Bei Druck von aussen unten bei offenen Augen plötzlich: „der Alexanderplatz, Häuser, Menschen (halbe Meile weit).

Der Versuch warde 3 mal wiederholt mit gleiehem Resultat. Bei Schluss „Nichts"; bei Druck Häuser oder Blätter. Das dritte Mal Buchstaben: "ach so gross", "lateinisch".

30. October. Bei Schluss: „Nichts".

Bei Druck: "Nur Schneewolken mit Streifen".

13. H..... Bei Schluss: Thiere, Kuhlopf, verwandelt sich jetzt in einen Löwen, Hunde, Pferde ete.

Bei Druck: Aehnliches.

30. November. 1. Höhepunkt des Deliriums. Sieht spontan Eichkätzchen.

Bei Schluss: Wagen, Pferde ete.

Bei Druck (liest): „Actiengesellschaft" etc., schwarze Buchstaben.

*) Diese Frage stellte der Patient! 
2. Schon bei Schluss liest er Gedrucktes, 4 Zoll grosse Buchstaben, hellblau auf schwarz.

Bei Druck unverändert.

3. Schluss: Weisse Damen, Thiere.

Druck (liest): "Grunewald", 6 Zoll grosse Buchstaben.

14. K...., las bei Druck Firmen auf Schildern and Aufschriften auf KKolli's.

15. H... sah anf blossen Augenschlussnichts, fingbei Druck an zu lesen. Schwarz auf weiss sei es: "Kassel, Kokliko" etc.

16. R...... siehtauf blossen Schluss nur weisse Punkte.

Bei Druck zunächst nichts. Bei starker Pressung des Bulbus nach unten: Ein C ein A, Zahlen, fängt an zu lesen.

17. M.... sah sowohl bei Druck, wie bei offenen $\Lambda$ ugen im Dunk len Schriften, die er fliessend herunterlas. Darunter französische und englische Worte.

Ausserdem ein Crucifix, Sarkophag, Statue seiner Sohwiegermutter ete.

18. K ...... II. 1. "Landschaft, Himmel, Mond und Sterne. Es ist kalt und nass". "Sehen Sie das?" "Nein das fühlt man doch".

2. Sieht Schriften, auch ein Strassenbild.

Soweit die Fälle, welche die Merkwürdigkeit zeigten, dass Schriften und Gedrucktes gesehen wurde.

Ich lasse nun die übrigen Versuchsprotokolle folgen.

19. K...

27. October. Spontan Männer, die ihn verhöhnen.

SchIuss: Nichts, Gestalten, die eine Nase machen.

Druck: Nichts, Flammen, ein Fels, von dem Wasser kommt, (lebhaft) ein Haus (greift danach), undeutliche Gestalten, Wolken.

29. October. Schlus s: Kaffeekanne, Pfützen, Himmel und Wolken, Sterne.

Druck: Verändert nicht erheblich. Einmal scheint er zu lesen.

Spontan viel Mlusionen.

30. October. (Nachts isolirt gewesen, jetzt etwas klarer).

1. Schluss: Sterne, Nachts dunkel.

Druck: Kirchthurm, neben dem Rauch aufsteigt, Strassen mit Bäumen und Blüthen, Sterne von der Form eines S.

2. Schluss: Nichts, wie Holz, die Finger sind warm. "Sehen Sie das?". "Nein, das fühle ich, sehen thue ich gar nichts".

Druck: Himmel, Wolken, zunehmender Mond und Sterne.

20. Raschke. 31. August. Offenbar Ebrius.

Schluss und Druck negativ.

1. September. Klagt, er träıme Nachts so stark, dass er aufwache.

Schluss ergiebt Nichts.

Druck: Hell, Sterne, Thiere, eine Art Krähen (und noch einige Gegenstände). Er weiss, dass das Phantasien sind. 
2. September. In Tobzelle. Erzählt von Verfolgungen, er wäre ja beschätzt worden, aber ,sie hätten mit den Zähnen geknirscht". Augenblicklich sieht er nur die anwesenden Personen, sieht weder am Fussboden, noch an der Wand auf Suggestion etwas, schildert die Umgebung richtig, nur hält er eine an der Decke angebrachte Luke mit grüner Klappe für ein Bild mit zwei Figuren.

Schluss: Schwarz, ein Stern, duster.

Druck: Dunkel, Thr Gesicht, das heisst, es ist Ihnen nicht ähnlich, das ist länglich. Ihr's ist ja riesig diek, auch hat dies hier einen grauen Bart, jetzt flimmert Alles. Eine Menge Damen! o das riesige Personal, vorn Bäume!

Nach Oeffnen: Na ist das möglich? Jetzt sind sie weg.

Bei zweimaliger Wiederholung sieht er stets bei Augenschluss nichts, bei Druck: Erst mich, meinen Anzug, Weste, Uhrkette dann Personen und Dinge, einen Lieutenant, eine ganze Suite. Er erklärt die Personen seien lebensgross, lebendig, wirklich.

21. Delirantin R...., Sängerin und Gesanglehrerin, die früher viel Cognac und Kümmel trank, jetzt mehr Bier und Rothwein, glaubt vorgestern gestorben zu sein. Das könne keine Täraschung sein. Bedeutet, dass sie doch jetzt lebe, meint sie müsse mittels Elektricität wieder erweckt worden sein.

Bei Druck: „Thr Gesicht, Thr Pincenez, Würmer, Perlen“.

22. St..... Glaubt, in der Geschützgiesserei zu sein. Sein Bruder ist Nachts gestorben, er ist unter Balken gerathen, der Meister ist mit dem Jungen zum Fenster herausgesprungen, beide haben sich aber nichts gethan.

Bei Druck sieht er: Ein Mädehen, Artillerie, einen Lieutenant, Pferde, mehr Artillerie.

Nachmittags ist er in höchster Excitation, schlägt unaufhörlich mit der Faust gegen die Wand.

Bei Druck auf die geschlossenen Augen sieht er erst „Herrn Dr.'s Gesicht", dann ein, zwei, drei vier - 21 Männer.

Zwei Tage darauf ist er klar, Druck negativ. Was er gesehen, war Alles natürlich, als wenn es wahr wäre. „Ist es denn wahr?" „Ja, das weiss ich nicht".

23. P... Glaubt (in der Zelle) in der Fleischkammer zu sein, hält den Arzt für einen Kriminalbeamten, spricht viel von „Eis holen“, ohne momentan zo halluciniren.

Druck Vormittags: Wolken, Sonne, Schatten.

Druck Nachmittags (in höchster Excitation und Hallucination): Mann im Strohhut, ein Hampelmann, viel Hampelmänner, ein Zaun; schwarz und weiss, einen Mann mit Mistbrägen. Auf die Frage, ab das Alles wirklich da sei: "Gewiss, man sieht ja den Mist herumfliegen."

Am 29. Juni ist er klar, erinnert sich an Alles, weiss, dass es eingebildet war. Giebt an "der Mann mit dem Mistbrägen sei im Mond gewesen."

Bei Druck: War es erst duster, dann wurde es schimmrig, dann heller und dann kam Mond und Sonne.

24. H. ... Glaubt in seiner Wohnung zu sein, spricht mit seiner Frau, 
Als·die Wärter ihm zu trinken geben wollen, geräth er in höchste Angst und Wuth, ruft um Hülfe, man wolle ihn schlachten. „Das Messer haben sie ja schon in Händen." An diesem Tage war es nicht möglich, den Versuch mit dem Tobsüchtigen zu machen.

Am nächsten Tage morgens ist er ziemlich klar. Giebt über alles Erlebte Auskunft, weiss, dass es Täuschung war. Er zittert noch sehr stark und. ist ängstlich.

Bei Druck sieht er noch: Schildkröten, Hampelmann, Schlangen. Weiss aber, dass es nicht wirkliche Dinge sind.

Am nächsten Tage sieht er bei Druck: „Nur Farbenflecke."

Am 7. Juli sieht er bei Druck: Punkte, bunte Flecke, ein weisses Ding, gerade wie ein Karnickelkopf.

Am 8. Juli: Wie ein Zifferblatt, wie ein Stickmuster.

Am 9. Juli erst war die Probe negativ, er blieb dabei Nichts zu sehen.

Eine gewisse Uebererregbarkeit überdauerte hier also die kritisch eingetretene Klarheit um 4 Tage. Indess fällt auf, dass er am ersten Tage nach der Krise sich schon der subjectiven Natur seiner Visionen bewusst war, an dem dritten und vierten, nachdem schon am zweiten normal reagirt war, das Gesehene nur verglich mit bestimmten Dingen, ohne sie dafür zu halten. Das geht aus den Wendungen: "Wie ein Zifferblatt, wie ein Karnickelskopf" u. s. w. hervor.

25. Helm.... 6. Juli. Druck: Farbige Punkte, Viertelmonde, eine Puppe. "Wie sieht sie aus?" "Mit Kopf und Schwanz."

7. Juli. Obgleich er noch spontan hallucinirte und in vollem Wahn war (Zigeuner, Polizei) ergab Druck nur: Punkte, Wolken, Halbmonde.

8. Juli. Ganz excitirt, isolirt. Bei Druck: „Goldene Punkte, goldene Pickel, jetzt: Karren, Soldaten, 1-2-3-viel Soldaten. Da eine Fran mit einer Molle, ach die Haufen Menschen, eine Frau mit einem Kind, Droschkenkutscher, Husaren". Ohne Druck bei offenen Augen sieht er Ringe im Bett und sieht Thiere, "die es gar nicht giebt."

Nach Schlaf ist er am nächsten Tage klar. Jetzt auf Druck nur: Schwarze Wolken, runde Dinger, Punkte.

Am nächsten Tage Druck negativ.

Im Folgenden gebe ich nur kurz den Inhalt der Visionen bei Druck an:

26. H ..... 26. Juli. Morgens im Delirium. Druck: Längere Zeit nur "Farben" (blau) und Sterne, dann "2 Mädels", eine blau angezogen, sie kniet an der Brücke, um sie herum Gras, Soldaten, Bohnen. Alles ganz deutlich.

Mittags: Pferde, ein blacuer Reiter, knieender Jäger, 2 Maschinen, eine weiss und eine roth. Eine Fabrik. Patient wurde immer soporöser und starb am 31. Juli.

27. S .... 28. September. 1. Wenig ergiebig; Nichts, Nichts, Bretter, Wasser, Nichts.

2. gleich 0 . 
29. September. Primitiv, Himmel, Wasser, (nach längerer Zeit) Häụser, theils einstöckig, theils zweistöckig.

Nach Oeffnen ist Alles weg. "Er habe die Glasthür für Wasser gehalten". "Wo ist denn eine Glasthür?" "Ach, den Ofen meine ich".

28. Gr.......

1. Schluss: Ihr Pincenez, Ihre Kravatte, Ihre Haare, graue, schwarze, grüne Haare.

Stein, Kies, Porzellan, Röhren.

Dr uck: Garnitur, Kränze, Steine, Porzellan.

2. Schluss: Grünes Wasser, grüne Sterne, Bouillon, Brühe, kleine Nudeln. (Greift danach.) „Was machen Sie denn?" "Ich will essen". Stickmuster, grünes Laub, Bücklinge, Erbsen, geflickte Hose.

Druck: Dunkel, Sand, Flaschen, blaue Vasen, Säbel mit einem Kinde (lacht lebhaft), ein Messer, Perlen-Etui (roth $1 / 4-1 / 2$ Zoll entfernt), Bäume, Vasen. (Greift bei Schluss wie bei Druck mehrfach nach den Dingen.)

29. G..... Nach der Krise. 10. September. Druck: Blau, Sterne, wie Tapeten, Vögel, wie lauter flatternde Schwalben, schwarz und weiss, wirkliche Vögel, jetzt nur Punkte. (Er weiss, dass es Täuschungen sind.)

Nachher bei geschlossenen Augen ohne Druck noch: Sterne, Blumen, Wolken, wie eine Art Pferdekopf, jetzt schaukelt es sich, Mosaikpflaster.

11. September. Druck: Punkte, Sonnenstrahlen, Feuerstreifen. (Also primitiv.)

30. Aug. Sch ... Druck 10. November: Heu auf meinem Sack, Sterne, ein Finger, die Wand, grau mit grünen Blumen. Die Deche mit 2 Flammen und Kronleuchter. (Spontan: Thiere, Wasser von oben, 200 Menschen wie im Graben.)

11. September. Dunkel, nur Farben, Sonne, jetzt Grünes, nur Bäume, nur Farben, jetzt sehe ich Kaiser Friedrich's Palais und Kaiser Wilhelm's. Wenig Leute, aber Fuhrwerk.

12. September. Nichts, die Bäume so dureh, wieder Bäume. (Im Garten vorgenommener Versuch.)

14. September. Gleich 0.

17. September. Gleich 0 .

31. W.... 1. Strasse voll Menschen. Wagen, Omnibus, Heuwagen, 100 Schritt entfernt.

2. Mein Kopf, Fenster, Moritzplatz mit 2 Abortbuden. (Spontan hatte er Thiere gesehen und glaubte am Moritzplatz zu sein.) nicht giebt.

32. Witt. 2 Augen, Gesicht eines gewissen P., Thier, das es gar

Spontan: Illusionen, gelber Hund, bewegte Sandkörner, Kommandorufen, Tasthallucin. Aber Alles als Täuschungen erkannt.

33. P.... Luft, an 200 Herren und Damen, Hof, Leute, die Wurst ausrufen. Elektrische Drähte.

(Spontan: Glaubt zu nähen.) 
34. T . . . . 1. December. Buschwerk, Himmel, mehr Gebüsch, Alles weg. (Weiss, dass Alles subjectiv.)

35. L . . 15. Juni. Farben, immer noch, graues Wasser mit Dreck und and Silberschaum.

16. Juni. Gänse, Ketten, Kramme. gesehen.

17. Juni. (Klar.) Gleich 0 . Last hatte anch spontan viel Wasser

36. G... 30. Juli. Nichts, Steine, Schweinegruse.

31. Juli. Nichts.

37. M... 7. August. Schwarze Deibel's, lauter Pfaffen, jetzt bunte Damen, nun wird's schummerig.

Nachmittag: "Nichts sehe ich". "Jetzt?" "Gott, das lohnt sich nicht den Dreck zu beschreiben". "Sehen Sie Menschen?". „Nein, es sind keime Menschen, nur Kinder; jetzt laufen doch ein Paar Menschen vorüber. Ein Soldat war dabei.

8. August. (Erschöpft.) Duster, wie Bäume, sonst kann ich Nichts sehen.

9. September. (Sehr erschöpft.) Gleich 0.

38. H . . . . . Wie Fragezeichen, Wald. Sonst negativ.

39. Ack..... Zwei am Grabe sitzende Menschen. Die Sonne scheint. Eine Frau mit Hut voll Blumen. (Spontan hörte er Miauen. Traum (?) von Heuwagen, Pferden und Schiff. Personenverkennung.)

Nach Oeffnen:. Ich: „Wo sind die Menschen hin?" Er: "Die sind nach Hause gegangen". Ich: „Und das Grab?" Er: „Das ist weg". Ich: „Es war wohl nur Einbildung?" Er: "Nein, ich habe es wirklich gesehen". Ich: "Sie hatten doch die Augen geschlossen?" Er: "Nein, ich hatte die Augen auf."

40. H. . . . sah den Belleallianceplatz, Häuser, Officiere etc. Behauptete nachher, der Arzt sei mit ihm dorthin gegangen.

\section{Zur Auffassung der mitgetheilten Visionen.}

Es gilt nun vor allen Dingen, die Auffassung der beschriebenen Erscheinungen als "Druckvisionen" zu sichern, d. h. den Nachweis zu führen, dass wirklich der Druck das auslösende Moment war.

Zunächst könnte man glauben, es handle sich einfach um Fortsetzung der spontanen Visionen, die nicht in Folge des Druckes, sondern während des Druckes aufgetreten seien.

Dagegen spricht indess schon der Umstand, dass in einer ganzen Reihe von Fällen die Versuche in Zeiten von remittirenden oder mindestens spärlichen Hallucinationen vorgenommen sind. Bekanntlich finden sich im Säuferwahn namentlich morgens Perioden, in denen die Production der Sinnestäuschungen ganz aufhört oder sehr nachlässt. In solchen Fällen gelang es nun doch häufig durch Druck Visionen auszulösen. In 5 Fällen war sogar das Stadium spontanen Hallucinirens schon ab- 
gelaufen und dennoch waren noch 10 bis 24 Stunden danach positive Ergebnisse der Druckversuche zu erzielen. Die Möglichkeit, solche artificiellen Visionen zu erzengen, überdauerte in diesen Fallen das Stadium spontanen Hallucinirens um eine gewisse Zeit. Umgekehrt konnte ich nachweisen, dass bei einem Patienten die artificiellen Visionen um einen Tag den spontanen vorausgingen. Bei Helm...... hatten wir am 6. Juni zwar Tremor, Schweiss, Angst verzeichnet, aber sein Bewusstsein noch ungetrübt gefunden. Trotzdem sah er auf Druck: Farbige Punkte, Viertelmonde, eine Puppe mit Kopf und Schwanz. Erst am 7. brach dann das eigentliche Delirium mit starken Sinnestäuschungen aus.

Aber auch für diejenigen Fälle, in denen die Versuche in den Zeiten spontanen Hallucinirens vorgenommen wurden, lässt es sich evident machen, dass es sich bei den aufgetretenen Erscheinungen um ganz etwas Anderes, als um einfaches spontanes Weiterhalluciniren handelt. Diese Evidenz ergiebt sich aus der Verschiedenheit des Inhalts und Charakters der hier als durch Druck provocirt hingestellten Visionen von dem der spontanen. Da eine darauf gerichtete Betrachtung zugleich mit bei der Zurückweisung einer zweiten Erklärungsmöglichkeit der ganzen Erscheinung ins Gewicht fällt, empfiehlt es sich, letztere sogleich mit in Rücksicht zu ziehen.

Man könnte nämlich gegen die hier vertretene Auffassung die mitgetheilten Gesichte auf einen anderen Factor, nämlich den blossen Lichtabschluss zurückführen wollen.

Es ist bekannt, dass Dunkelheit und Augenschluss bei manchen Geisteskranken genügen, um Hallucinationen herbeizuführen, während andere gerade bei offenen Augen Erscheinungen haben. Die Exacerbationen der Delirien bei Nacht, die in Einzelhaft auftretenden Gehörshallucinationen, die Neigung selbst Gesunder, im Dunklen Geister und Anderes zu sehen, sind Thatsachen, welche den Hallucinationen begünstigenden Einfluss der Abhaltung äusserer Sinnesreize illustriren. Diese Thatsachen bieten sich auch leicht unserem Verständniss. Bei Lichtzutritt strömt den. Augen eine Fülle von objectiven Reizen zu, sind sie auch nicht immer siegreich gegenüber concurrirenden subjectiven Empfindungen, so ist doch mindestens eine hemmende Wirkung anf letztere einleuchtend. Dazu kommt, dass der Anblick der Wirklichkeit dem noch nicht ganz getrübten Bewusstsein den überhaupt noch erreichbaren Grad von Kritik verleiht, vermöge deren das Spiel der Einbildungen eingedämmt und verhindert wird, die Möglichkeitsgrenze zu weit zu überschreiten.

Geht man von der bestimmteren Annahme ans, dass bei diesen 
Hallucinationen im Dunklen Eigenerregungen der Netzhaut im Spiel sind, so kann man für den Thatbestand eine noch exactere, sich an das Fechner'sche Gesetz anlehnende Erklärung geben. So macht Jolly bei Besprechung der schon erwähnten Naegeli'schen Visionen nach Verbrennung der Hornhaut geltend, dass sich der nervöse Sehapparat bei Dunkelheit im Zustande der Hyperästhesie befinde, insofern im Dunklen geringere Lichtunterschiede wahrgenommen werden, als in der Helligkeit. In Folge dessen werden die immer vorhandenen Eigenerregungen der Retina resp. centraler gelegener Theile erst im Finstern empfunden. *)

Die nächtlichen Exacerbationen der Sinnestäuschungen bei den Alcoholdeliranten kommen nun zwar nicht allein auf Rechnung des Lichtabschlusses. Denn haben auch die Deliranten meist keinen eigentlichen Schlaf, so befinden sich doch auch viele von ihnen Nachts nicht im Zustande vollen Wachens. Diese Deliranten geben oft fälschlich an, sie hätten ihre Visionen "geträumt", oder richtiger im Halbschlaf gehabt. In der That wird auch bei diesen - bei anderen allerdings nicht sich Nachts jener Nachlass der Grosshirnthätigkeit finden, welcher sich beim gesunden Schlafenden als starke Herabsetzung der Sinnesempfindlichkeit und der Urtheilsfunction kundgiebt, also jener Zustand, in dem geträumt wird - natürlich in viel geringerem Grade als beim Gesunden. Jedenfalls kommt diese centrale Beeinträchtigung, wenn sie auch der im Vollschlaf nicht ebenbürtig ist, mit für die Production von Sinnestäuschungen in Betracht.

Als reine Belege für durch Lichtabschlass bedingte Visionen kommen daher, mit einer zunächst nicht zu urgirenden Einschränkung, nur diejenigen Fälle in Betracht, in denen am Tage ohne Schläfrigkeit, auf Lidschluss Gesichtserscheinungen auftreten, während sie bei offnem Auge fehlten. Solche Fälle sind aber in der That nicht selten.

Schon die Angaben einiger Kranken gingen dahin. L.... liess im Halbdunkel die Lampe brennen, um die ihn quälenden Erscheinungen zu bannen. Bar.....'s Gesichte verschwanden, sobald er die Augen aufmachte. Dass Lichtzutritt umgekehrt Sinnestäuschungen begünstigt hätte, wie es von anderen Psychosen berichtet wird, fand sich bei unseren Deliranten nie. Im höchsten Falle "nützte Augenschluss Nichts". So gab Gr..... an, dass bei Augenschluss die Erscheinungen verschwanden, ,andere traten in ihre Stelle".

*) Jolly, Ueber Gesichtserscheinungen in Folge ron Verbrennung der Augen. Allg. Zeitsehr. f. Psych. XL. 
Sind nun vielleicht alle unsere "Druckvisionen" in Wahrheit Nichts als Dunkelvisionen?

Diese Möglichkeit scheint sofort widerlegt zu werden durch die Thatsache, dass die Visionen auch bei Druck auf die offenen Augen eintreten. Dieser Meinung gab ich mich zunächst auch hin.

Indess ein an mir selbst und dann an anderen Gesunden gemachter Versuch belehrte mich, dass es eine Täuschung wäre, hierbei den Lichtabschluss für eliminirt anzusehen. Wenn ich von oben und unten oder von der Seite mein offues Auge drückte, so fand ich, dass bald die Aussenwelt undeutlich von der Peripherie zum Centrum wird, schliesslich ganz verschwindet und dann im dunklen Sehfelde subjective Lichterscheinungen auftreten. Der Opticus wird also durch den Druck unempfindlich für äussere Lichtreize. Er verhält sich offenbar auf Druck hier ähnlich wie die sensiblen Nerven gegenüber den Anaestheticis dolorosis. Eine Einwirkung hebt die Leitungsfähigkeit für peripher kommende Reize auf, von der Stelle der Einwirkung selbst werden Sensationen centralwärts befördert. ${ }^{*}$ )

Ob hier die Wirkang direct in Compression des Opticus besteht, oder in der Abknickung der Gefässe und dadurch bedingter Blutabsperrung ist zweifelhaft, soviel aber steht fest, dass das bei geöffneten Lidern gedrückte Auge nach einer gewissen Zeit einem geschlossenen Auge in Bezug auf Lichtabschluss gleichzusetzen ist." ${ }^{*}$ ) Dazwischen liegt allerdings eine Zeit, in der central noch gesehen wird, peripher schon Verdunklung und Lichtstaub aufgetreten ist. Könnte man also mit Sicherheit sagen, dass Visionen schon in dieser Zeit eingetreten seien, so wäre das allerdings beweisend. Indess ist das natürlich bei einem Deliranten schwierig.

Mehr Aussicht scheint ein anderer Weg zur Entscheidung der Frage zu haben. Man kann das Auge schliessen lassen, ohne es zu drücken oder den Versuch im Dunklen bei offnem Auge machen.

Der blosse Augenschluss bedeutet nun zunächst auch nicht eine absolute Ausschliessung mechanischer Wirkungen. Nicht nur das Lid selbst übt einen Druck aus, $\left.{ }^{*}{ }^{* *}\right)$ sondern mit der Richtung der Aufmerk-

*) Helmholtz verglich den gedrückten Opticus mit dem gedrückten Ischiadieus, der auch für periphere Reize undurchgängig wird, aber das der Druckfigur entsprechende Kribelgefühl liefert. Physiol. Opt. II.Aufl. 1887. S.238.

**) Nur der Unterschied besteht, dass beim Druckversuch Reize peripher von der Retina fortfallen, während bei Augenschluss Erregungen von den vor der Retina gelegenen Theilen, Glaskörper etc. nicht auszuschliessen sind.

***) Dass dieser Druck ganz erheblich ist, kann man bemerken, wenn man 
samkeit auf das Sehfeld sind zweifellos Spannungen der äusseren und inneren Augenmuskulatur verbunden (was also selbst bei offnem Auge im Dunkelzimmer im Betracht kommt). Bei der blossen Accommodation wird an der Netzhaut gezerrt. Indess, macht auch diese Erwägung fraglich, ob die bei blossem Augenschluss auftretenden Erscheinungen allein auf Lichtabschluss zurückzuführen sind - besonders bei dem vermuthlich überempfindlichen Delirantenauge - so kommt sie doch nicht in Betracht für die Frage, ob ein bestimmtes Phänomen durch ausseren Druck oder durch Augenschluss veranlasst ist. Erst wenn bewiesen ist, dass Druck irgendwo für sich allein dies Phänomen erzengt, werden die mit Augenschlass verbundenen mechanischen Wirkungen mit für die eintretenden Erscheinungen verantwortlich gemacht werden können. $O b$ aber bei unseren Deliranten der äussere Druck die Visionen auslöst, dafür wird der Versuch mit blossem Lidschluss entscheidend sein.

Praktisch stösst nun dieser Versuch auf eine Reihe Schwierigkeiten. Nicht häufig wird es gelingen, einen unruhigen Deliranten durch blosse Aufforderung zu anhaltendem Augenschluss zu veranlassen. Gelingt es, so kneifen sie oft die Augen so krampfhaft zusammen, dass der Druckfactor wieder eingeführt ist.

Am meisten empfiehlt es sich, ein mehrfach gefaltetes Tuch über das Auge zu legen. Man muss sich aber bewusst sein, dass auch dieses nicht ohne jede Druckwirkang ist.

Auf diese Weise habe ich Folgendes ermittelt: Ein Theil der Deliranten hatte schon bei bloss tuchbedecktem geschlossenem Auge Gesichtserscheinungen. Ein Pat. sah alle möglichen Gegenstände: Porzellan, Säbel, Etuis, Garnituren, Kränze. Zwei Mal hatten wir sogar Visionen, die den Druckrisionen sehr ähnlich sahen, es wurden Schriften gesehen. Ebenso sah der einzige Patient, mit dem ein Versuch im Dunkelzimmer gelang, der allerdings lebhafteste Hallucinant, den wir überhaupt hatten, schon ohne Druck alles Mögliche und fing auch an zu lesen, was er minutenlang fortsetzte.

Er gestand aber nach seiner Genesung, dass er schon als Kind im Dunklen allerlei Fratzen gesehen hätte. Er war also eine in dieser Richtung besonders ansprechbare Natur.

Dem gegenüber steht aber eine andere Reịe von Fällen, die zum Theil oben verzeichnet sind, in denen ohne Druck

den Finger fest gegen das untere Lid legt und nun abwechselnd das Auge schliesst und öffnet. Bei Schluss tritt der Bulbus zurück, bei Oeffnung drängt er den Finger mit nicht geringer Gewalt nach vorn. 
andauernd und wiederholt Nichts gesehen wurde, nach Druck sofort. Ich erinnere an R... (No. 20), der bei 3 an demselben Vormittag vorgenommenen Versuchen immer wieder bei SchJuss Nichts sah, bei Druck sogleich Visionen hatte. Ebenso P..... (No, 12), K...... (No. 18), R....... (No. 16), H... (No. 16) u. s. w. Dabei muss man den Schlussversuch vor dem Druckversuch vornehmen. Denn nachdem einmal das Ange durch Druck gereizt ist, visionirt es noch einige Zeit bei aufhörendem Druck, ja wie einige Versuche zeigten, bei offnem Auge in demselben Sinne fort. Dies entspricht auch ganz der Persistenz der Druckfigur bei Gesunden nach Aufhören des Druckes.

Ferner traten in einer anderen Reihe von Fällen die Visionen nicht schon auf Lidschluss, sondern erst nach längerem und verstärktem Drücken auf. Ja dreimal zeigte sich, dass nicht jeder, sondern nur besonders gearteter Druck wirkte (so bei P..... nur seitlicher).

Dass aber selbst in den Fällen, in denen schon Lidschluss Gesichte auslöste, die auf Druck eintretenden auch durch den Druck erzengt waren, zeigt ein Blick auf Inhalt und Charakter der mitgetheilten Visionen, deren Verschiedenheit von den spontanen auch das in Aussicht gestellte weitere Argument gegen die Meinung, es handle sich nur um Weiterhalluciniren während des Versuches, abgiebt.

Die mitgetheilten Visionen tragen zum grossen Theil ihre Herkunft aus der Druckfigur auf der Stirn. Ich erinnere an das häufige Auftreten der gelben leuchtenden Scheibe, die zu den Hauptingredienzien des Phosphens gehört, an die herrschende Rolle von Sonne, Mond and Sternen. $\left.{ }^{*}\right)$

So wenn P... den Mond sah, und dann einen Mann im Mond. Oder wenn Schm... angiebt, die gesehenen Zahlen hätten wie auf einer "Lottomarke" gestanden, es habe sich ein heller Fleck, wie ein Pfennig gross, gezeigt und darin seien die Zahlen zu lesen gewesen.

Oder wenn ein Dritter ein Grab bei Sonnenschein sah u. s. w. Sonne, Mond und Lottomarke sind hier offenbar die erwähnte gelbe Scheibe. Der Himmel, eine so ungemein häufig wiederkehrende VisionWolke, Nebel, Sterne, die man als meteorische Frscheinungen zusammen, fassen kann, ferner leuchtende Schlangen, goldene Knöpfe, Rosetten, verrathen alle ihre Genealogie von der Druckfigur. Wo Häuser, Menschen, Thiere gesehen wurden, ist diese nicht mehr ersichtlich.

Ferner erklärt sich die auffallige Häufigkeit von Geschriebenem und Gedrucktem ungezwungen als illusorische Verarbeitung des Purkinje-

*) Ich habe in die mitgetheilten Versuchsprotokollen gar nicht einmal alle derartigen Angaben wegen ihrer Häufigkeit aufgenommen. 
schen Phosphens. Insbesondere liefern die zahlreichen kleinen Vierecke in einer der von Parkinje aufgezeichneten Figuren ein sehr geeignetes Material hierzu. Bei einiger Phantasie, wie man sich vulgär ausdrückt, können sie wohl für Bachstaben genommen werden.

Nun wurde aber zweimal schon bei Schluss des tuchbedeckten Auges gelesen? Einmal sogar bei offenem Auge im Dunkelzimmer? Gewiss! Zweifellos ist bei manchen Deliranten die Erregbarkeit des Opticus so erhöht, dass entweder schon der mechanische Reiz, den Lidschluss und Tuch verursachen, die Anspannung der Muskeln, oder gar die Eigenerregungen der Netzhaut genügen, am dieselben Erscheinungen wie bei Fingerdruck zu Stande zu bringen. Nachdem einmal für eine Reihe von Fallen die Abhängigkeit bestimmt gearteter Visionen von mechanischem Reiz des Opticus erwiesen ist, kann man mit einigem Recht gleichartige Erscheinungen, welche ohne solche äussere Einwirkung sich finden, der Wirksamkeit entsprechender innerer Reize, Druck des Lides etc. und einer möglicherweise in Folge von Hyperämie und Lymphstaunng: vorhandenen Erhöhung des intraokularen Druckes zuschreiben.

Dass ausserdem Lichtabschluss überhaupt begünstigend für das Eintreten von Hallucinationen in Mitwirkung tritt, ist nicht zu leugnen. Es kommt aber zunächst nicht darauf an, zu beweisen, dass Visionen, wie die beschriebenen, $\mathrm{n}$ ur durch Druck entstehen können, sondern dass sie auch durch Druck entstehen. Was sagt uns aber letzteres Neues? Was sagt es uns mehr, als die Visionen bei Augenschluss uns schon lehrten?

Ich glaube der Unterschied liegt in Folgendem: Dass die Erscheinungen der Deliranten bei Augenschluss von subjectiven Erregungen der Netzhaut ausgehen, ist eine blosse Vermuthung. Niemand hat bisher einen ätiologischen Zusammenhang zwischen ihnen und peripheren Erregungen als Thatsache erwiesen. Wenn Jemand behaupten würde, sie seien rein central entstanden, könnten wir ihn nicht widerlegen.

Bei den Druckvisionen hat man dagegen den strikten Nachweis einer ätiologischen Abhängigkeit der Hallucination von peripherem Reiz. Den Reiz erzeugen wir selbst. Wir kennen seine Wirkang auf den Gesunden. Wir sehen hier seine Wirkung auf den Kranken.

Erst nachdem so für eine Gruppe von Erscheinungen die Herkunft von notorischer peripherer Reizung festgestellt worden ist, nachdem ein bestimmter Charakter derselben, bedingt durch eine besondere Art des Reizes, erkannt worden ist, wird es wahrscheinlich, dass andere gleichartige Erscheinungen, bei denen der periphere Reiz nur vermathet werden kann, auf dieselbe Weise zu erklären sind. 
Darin also, dass hier der Ursprung von Sinnestäuschungen nicht aus hypothetisch hinzuconstruirten Reizen des Sinnesorgans wahrscheinlich gemacht, sondern aus aufgezeigten, ja selbst erzeugten Reizen erwiesen wird, liegt, wie ich glaube, der Zuwachs der Erkenntniss, den die Druckvisionen zu den "Nachtphantasmen" hinzubringen.

\section{Das Druckverfahren als Methode zum Studium der Hallucinationen.}

Aber die besprochene Versuchsweise sichert nicht nur die Thatsache eines peripheren Ursprungs von Trugwahrnehmungen, sondern sie ist auch eine brauchbare Methode zum Studium der Hallucinationen, zunächst bei den Alkoholdeliranten, und damit auch der Hallucinationen im Allgemeinen.

Bevor ich dies näher ausführe, möchte ich auf einen diagnostischen Nutzen derselben hinweisen. Wir haben sie mehrfach bei Personen angewendet, die des Deliriums verdächtig waren, aber Hallucinationen in Abrede stellten. Der positive Erfolg sichert in diesen Fällen das Vorhandensein von Hallucinationen. Entweder hatten die Betreffenden ihre Hallucinationen vergessen, oder sie dissimulirten. Dann hätten sie unter dem lebendigen Eindruck der Bilder die Dissimulation aufgegeben. Oder aber die spontanen Sinnestäuschungen waren noch nicht aufgetreten. In solchem Fall ist die Ylethode prognostisch zu verwerthen. Positiver Erfolg weissagt dann baldigen Ausbruch der Delirien. *)

Der Vorzug nun des Augendruckes als Methode zum Studium der Sinnestäuschungen scheint mir in Folgendem zu liegen.

Für die Kenntniss der Trugwahrnehmungen der Deliranten sind wir sonst zum grossen Theil auf nachträgliche Berichte d. h. Erinnerungsbruchstücke angewiesen. Damit sind aber alle Erinnerungsfälschungen, und zwar zu den normalen noch die pathologischen, eingeführt.

Ferner sind in die Erlebnisse, die uns der Patient von gestern oder der Nacht erzählt, viele wirkliche Vorgänge eingewoben. Wir sahen schon, wie oft ein Bericht über schreckliche Verfolgungen die illusorische Verarbeitung der zur Internirung vorgenommenen Massnahmen der Angehörigen oder der Polizei darstellt! Wir wissen daher nicht,

*) Ein solcher Fall ist oben mitgetheilt. 
was wir auf Rechnung der Wirklichkeit, was auf Rechnung der Tăuschungen bringen sollen.

Was wir als Zeugen gegenwärtiger spontaner Sinnestäuschungen beobachten, ist von dem ersten Nachtheil frei, und insofern zweifellos eine reinere Quelle. Aber das zweite Moment, die Beeinflussung durch die äussere Umgebung beeinträchtigt auch hier eine ganz eindeutige Auffassung der Seelenvorgänge der beobachteten Person.

Dem gegenüber liefert die Prüfung mit Druck die unmittelbaren Schilderungen über gegenwärtige Seelenerlebnisse. Sie werden gewissermassen in statu nascendi offenbart. Damit fallen alle Auslassungen und Entstellungen, die jeder Reproduction, insbesondere aber der eines Deliranten anhaften, weg.

Zweitens aber sind die Versuchspersonen von allen Aussenweltseindrücken abgeschlossen, sie sind alle unter die bekannten gleichen Bedingungen gestellt, nämlich die, welche normalerweise die Druckfigur liefern. Damit sind die Voraussetzungen eines aussichtsvollen Experimentes erfüllt.

Wir lassen auf den Deliranten einen in seiner normalen Wirkung bekannten Reiz wirken, schliessen Nebenreize aus und prüfen, wie die Psyche denselben verarbeitet.

Schliesslich ist die Methode schneller und einfacher ausführbar, als das Ablauschen und Erspähen spontanen Hallucinirens.

Andererseits müssen wir aber berücksichtigen, dass wir den Deliranten unter künstliche Bedingungen gesetzt haben, dass wir gewissermassen eine Seite seines Bewusstseins isolirt und rein herauspräparirt haben: den Vorstellungsmechanismus, und zwar in seiner Reaction auf eine ganz besondere und bestimmte Beeinflussung.

Denn während des Versuches ist der Delirant in einem Zustande vorübergehender Sammlung. Er hat das dunkle Bewusstsein, dass der Arzt etwas mit ihm vornimmt. Damit ist er aus seiner gewöhnlichen Gefühlslage herausgerissen. Ausserdem entziehen wir ihn den natürlichen Einflüssen seiner Umgebung. War dieses einerseits ein Gewinn für die Reinheit des Experimentes, so fordert es andrerseits bei Verwerthung der Resultate eindringliche Berücksichtigung. Es muss bei Würdigung der Differenzen, welche zwischen künstlichen und spontanen Visionen bestehen, in Rechnung gebracht werden.

\section{Ergebnisse des Verfahrens.}

Die vorliegenden Versuche können natürlich nur einen Anfang zur Erforschung der Sinnestäuschungen auf dem bezeichṇeten Wege dar- 
stellen. Die Gesichtspunkte erwuchsen mir ja erst im Verlauf der Untersuchung.

Indess geben sie in einigen Richtungen schon recht deutliche Aufklärungen.

Ueberblickt man die bei Druck aufgetretenen Visionen, so zeigen sie folgende Eigenthümlichkeiten:

Eine nicht kleine Gruppe der Visionen zeigt deutlich ihren $\mathrm{Zu}$ sammenhang mit Wahrnehmungen, die der Patient vorher bei offenem Auge gehabt hat. Nicht selten ereignete es sich, dass derselbe zuerst angab, er sehe mein Gesicht, meine Haare, mein Pincenez, oder die Fenster, die Bäume des Gartens etc.

Solche Angaben traten immer nur am Beginn des Versuches auf. So sah R..... "Dunkelheit, Ihr Gesicht, das heisst es sieht Thnen nicht ähnlich, Thres ist ja riesig dick und das hier ist länglich, es hat auch einen granen Bart, jetzt flimmert Alles. 0, das riesige Personal! Eine Menge Damen." Eine Viertelstunde später sah derselbe: „Sie, Ihren Anzug, Ihre Uhrkette, Weste, jetzt ein Lieutenant, eine ganze Suite." Ein dritter Versuch bei ihm war ganz analog. Weitere Beispiele findet man unter den Versuchsaufzeichnungen.

Es bieten sich verschiedene Erklärungen für diese Erscheinung. Es könnte sein, dass viele Deliranten abnorm lange und abnorm intensive Nachbilder von dem Gesehenen zurückbehielten. Oder es könnte sich um eine Art Autosuggestion handeln. Der Patient weiss, dass ich vor ihm stehe und dies Wissen könnte seine Auffassung des im Gesichtsfeld Erscheinenden bestimmen. Wahrscheinlich wirkt Beides zusammen. Die Frage liesse sich durch Versuche weiter verfolgen. Entscheidend für die zweite Erklärung wäre ein Versuch, bei dem der Experimentator von vornherein hinter der Versuchsperson stände und diese dennoch angäbe ersteren zu sehen. Denn dann könnte von einem Nachbilde keine Rede sein.

Interessant ist in R....'s Fall, wie sich das zuerst Geschaute gleich verwandelte, ihm gewissermassen entglitt.

Eine zweite, viel kleinere Gruppe zeigt Uebereinstimmung mit den spontanen Einbildungen. Ein Delirant batte Morgens geglaubt, auf dem Moritzplatze zil sein, bei Druck sah er denselben wieder mit allen Details. Ein Anderer, der sich allseitig von Wasser bedrängt gesehen hatte, sah auch bei Druck: Dreckwasser mit Silberschaum.

Weit überwiegend ist die dritte Gruppe: sie enthält Dinge, die weder mit den normalen noch den trügerischen vorangegangenen Wahrnehmungen in Zusammenhang stehen. Ueber das, was so gesehen wurde, habe ich eine Statistik aufgestellt, 
die natürlich nur in grossen Zügen verwerthbar ist, aber auch dann ganz auffällige Unterschiede von den spontanen Hallucinationen und manches Beachtenswerthe liefert.

An erster Stelle, der Häufigkeit nach, stehen diejenigen Erscheinungen, die ihren unmittelbaren Anschluss an die normalen Druckerzeugnisse am deutlichsten offenbaren: Himmel, Sonne, Mond, Sterne, Wolken, Blitze, Regen, kurz "meteoris che" Erscheinungen. Sie finden sich gewöhnlich beim Beginn des Versuches.

An zweiter Stelle kommen die besprochenen Schriften, gedruckte oder seltener geschriebene Worte, einzelne Buchstaben oder Zahlen. Dieselben wurden bald fliessend heruntergelesen, bald mühsam buchstabirt, bald für unleserlich oder mehrdeutig erklärt. Ein Theil der gelesenen Worte war ganz sinnlos.

Die Buchstaben wurden von fast Allen als sehr gross, 1-6 Zoll, beschrieben, die Entfernung auf 6-15 Zoll taxirt, sie wurden schwarz auf hellem Grunde (8mal) oder hell auf dunklem Grunde (5 mal) (gelb oder weiss) gesehen. Einmal grün auf gran.

An dritter Stelle folgen menschliche Gestalten, bald bunt als Artillerie, Husaren, Lieutenants, vorwiegend überhaupt Soldaten, bald schwarz als unbestimmte Gestalten, Deibels, Pfaffen und Aehnliches. Bald einzeln, bald in grossen Massen. Ein Delirant zählte 21 Männer.

Der Frequenz menschlicher Gestalten kommt fast gleich die lebloser Gegenstände, Gebände, Schmuck* und Gebrauchsgegenstände aller Art.

Was nun sehr bemerkenswerth ist: Erst jetzt folgen Thiere und in gleicher Zahl Pflanzliches: Bäume, Grünes, Blumen, also in verhältnissmässig geringer Menge. Ratten und Mäuse wurden aufälligerweise bei den Druckvisionen überhaupt nicht gesehen. Oefters kamen ganze Situationsbilder, Strassenscenen, Plätze mit Fuhrwerken und Menschen, also Bilder gemischten Inhaltes zur Wahrnehmung.

Wie war der Charakter des Gesehenen in körperlicher Hinsicht?

Das Gesehene war fast durchweg plastisch. Flächenhafte Bilder wurden selten und dann gerade in den beginnenden und leichteren Fällen gesehen.

Auch hatten alle Deliranten leuchtende und farbige Gesichte, wenn auch natürlich schwarze und dunkle Gestalten mit unterliefen.

Es handelte sich meist um natürliche Grösse und Alles bekam einen ganz bestimmten Ort ausserhalb des Körpers.

Geistig charakterisirte sich das Gesehene durch folgende Eigenschaften: 
Es war zusammenhanglos. In vielen Fällen zeigte sich schon das Nebeneinander, das gleichzeitig Gesehene, als ein Zusammengerathenes und nicht als ein Zusammengehöriges, so wenn Perlen, Würmer und das Gesicht des Arztes, oder Gänse und eine Kette, oder Hampelmänner und Schlangen zusammen wahrgenommen wurden. In anderen Fällen trat allerdings, wie schon bemerkt, ein ganzes Situationsbild vor Augen, dessen einzelne Elemente zusammengehörige, in der Wirklichkeit oft verbundene Theile eines Ganzen darstellten. So: eine Strasse mit Häusern, Omnibus, Droschken, Verkäufern, oder ein ganzer militärischer Aufzug mit allem Zubehör. In solchen Fällen wird der Gesammtempfindungscomplex in einem Sinne verarbeitet.

In dem Nacheinander bestand fast nie ein Zusammenhang oder ein ganz wunderlicher. Zum Beispiel berichtete ein Pneumoniker: „Ich sehe einen Löwen, jetzt kommt eine Eisenbahn mit zwei glühenden Angen vorn, jetzt springt der Löwe über die Eisenbahn." Sonst aber handelte es sich stets um jene unter sich nicht verknüpften Wandelbilder, wie sie einen Theil der Visionen, welche spontan vorkommen, ausmachen. Nie reihten sich aber die Bilder zu einem Vorgang zusammen im Sinne der spontan auftretenden traumähnlichen Erlebnisse.

Nicht nur ein Znsammenhang der Visionen unter sich fehlte, sondern auch ein erkennbarer Zusammenhang mit dem Vorstellungsleben des Deliranten. Die beiden Ausnahmen sind schon besprochen, nämlich das seltene Wiederkehren spontaner Hallucinationen und das häufigere Wahrnehmen von den Dingen und Personen, die den Kranken umgeben und von ihm unmittelbar vor dem Versuch bei offenen Augen gesehen waren. Meist entsprach das auf Druck Gesehene nicht dem, was den Deliranten spontan sonst beschäftigte.

Dass es sich insbesondere nicht etwa um sensualisirte Vor stellungen, um sinnliche Realisirung von Gedanken handelte, geht überzengend aus dem häufigen Vorkommen von Undeutlichem, Unentzifferbarem hervor. Wer das sieht, woran er denkt, wird nicht im Zweifel sein, was er sieht. Auch wird er nicht ganz sinnlose Silbencomplexe, verbildete and verzerrte Dinge sehen.

Die Natur des Visionirten scheint also wesentlich von der Art der Erregung abzubängen. Was annähernd in Form und Farbe den vorhandenen Sensationen entspricht, giebt für diese das assimilirende Material ab. Natürlich sind Form und Farbe nicht so zwingend, dass nun die individuelle Veranlagung bei der Auffassung gar nicht zur Geltung käme. Alles, was hallucinirt wird, besteht ja aus Elementen, die in der seelischen Vergangenheit des Hallucinirenden 
eine Rolle gespielt haben. Daher wird sich diese nicht in der Art der Visionen durchaus verleugnen können. So las z. B. ein gebildeter Delirant zum Theil französische und englische Sätze. Aber der Inhalt dieser Sätze stand ansser jedem Zusammenhang mit dem, was ihn sonst während seines Deliriums beschäftigte. Und das ist es, worauf Werth zu legen ist.

Ganz anffällig ist ferner, dass der Inhalt der Druckvisionen durchweg nicht schreckhaft war. Es waren immer gleichgiltige Dinge und Vorgänge. Ueberhaupt fehlte nicht nur eine ängstliche, sondern jede Eigenbeziehung. Die Patienten verhielten sich wie Zuschaner bei einem Schauspiel, oder wie Jemand, den man in einen Guckkasten sehen lässt. Nur dass sie zuweilen nach dem Geschauten griffen, so jener Delirant, der nach den vermeintlichen Nudeln die Hand ausstreckte. Schon hieraus geht hervor, dass das Gesehene meist für real gehalten wurde. Mehrere hatten die Vorstellung, sie sähen durch ein Vergrösserungsglas, Anderen kam der Augenschluss gar nicht zum Bewusstsein, sie behaupteten nachher, die Augen offen gehabt zu haben. Wieder Andere erkannten, dass es sich um subjective, künstlich erzeugte Empfindungen handelte. So Einer: "das haben Sie mit dem Finger gemacht." Deliranten, die Landschaften oder Strassen sahen, glaubten mehrfach, man habe sie dorthin geführt and sie befünden sich wirklich am Orte ihrer Visionen. Wie sie das Gesehene verdachtlos mit in das Sitnationsbewusstsein hineinarbeiten, zeigte K..... Er sah bei Druck eine Landschaft, den Himmel, Mond und Sterne, sagte dann: "es ist kalt und nass". Ich fragte: "Sehen Sie das?" "Nein, das fühlt man doch." Also er bezog seine Temperaturempfindungen (es war wirklich an dem Tage kalt und nass) und die Gesichte auf dieselbe Wirklichkeit.

Für real also wird das Gesehene meist gehalten, es wird auch zuweilen Gegenstand des Wunsches und Interesses. Aber die Personen und Thiere agiren nicht gegen den Kranken, das, was vorgeht, gilt nicht $\mathrm{ihm}$.

Die Theile des Sehfeldes sind nicht in dem Grade bewegt, wie es gewöhnlich bei dem spontan Hallucinirten der Fall ist. Das beweisen schon die Schriften. Vor Allem wird von einem Schwanken und Wanken der Häuser und Gegenstände Nichts berichtet.

Ich fasse noch einmal kurz die Differenzen zwischen den Visionen bei Druck und den spontanen zusammen:

1. In den ersteren treten Thiere überhaupt sehr zurück. Speciell Ratten und Mäuse fehlen ganz. Leblose Gegenstände, Menschen u. s. w. überwiegen.

2. Der Inhalt ist durchaus nicht schreckhaft. 
3. Es fehlt überhaupt die Eigenbeziehung.

4. Es fehlt jeder Zusammenhang.

5. Das spontan so oft bemerkte Schwanken und Wanken fällt weg.

Was entnehmen wir dem ersten Punkt, dem Fehlen der Thiere, und wie erklärt sich diese auffällige Differenz von den Resultaten der Beobachtung spontaner Delirien?

Die Versuche beweisen, dass im Vorstellungsleben des Deliranten an und für sich durchans kein räthselhafter Hang zu einer Beschäftigung mit der Thierwelt besteht. Dass vielmehr sogar die Thiere zurücktreten gegen die Fülle anderer Gesichte.

Wenn also die spontanen Delirien ein davon so verschiedenes Bild liefern, müssen hieran Momente Schuld sein, die durch die Bedingungen der Druckversuche ausgeschlossen sind.

Welche das sind, ist ziemlich klar. Vor Allem fehlt während des Versuches der Affect: die Unsicherheit und Angst. Wir wiesen schon darauf hin, dass die Nähe des Arztes und das dunkle Gefühl, dass es sich nm einen Versuch handele, jene Gefühlserregungen vorübergehend bannen. Während des Versuches ist gewissermassen der Vorstellungsmechanismus isolirt. Es ist begreiflich, dass dieselbe Netzhauterregung, welche dem ruhigen Deliranten den Eindruck eines harmlosen Gegenstandes macht, von dem geängstigten als bedrohendes Thier appercipirt wird.

Ferner schliesst der Versuch alle Erregungen aus, welche diesseits der Retina entstehen, also die von den brechenden Medien kommenden, sowie alle Einflüsse gestörter Funktion der äusseren und inneren Augenmuskeln. Die Vermuthung also, dass von solchen Einflüssen (mouches volantes etc.) das häufige Sehen von Bewegtem und von Thieren herrühre, wird durch die Druckversuche zwar nicht bewiesen, aber gestützt, insofern sie ergeben, dass, wo jene Einflüsse ausgeschlossen sind, auch das Ueberwiegen von Bewegtem und Thieren fehlt. Dass insbesondere keine Mäuse und Ratten gesehen werden, erklärt sich aus dem Lichtabschluss. Die leuchtenden hin- und herschwirrenden Punkte, die bei gedrücktem Auge gesehen werden, wird nicht leicht Jemand für Mäuse halten. Bei concurrirendem Aussenlicht dagegen werden sich durch irgend welche Reizung der Netzhaut erzeugte bewegliche Punkte dunkel ausnehmen und daher eher die Dentung als Ratten oder Mäuse provociren.

Nun kommt aber hinzu, dass die unvermeidliche Art unserer Kenntnissnahme von den spontanen Visionen eine Verschiebung zu Gunsten der Thiere bedingt. Wir bekommen auf zwei Wegen vom Innenleben des Deliranten Kenntniss: 1. durch seine An- 
gaben, 2. durch sein Verhalten, d. h. seine Reactionen auf das Wahrgenommene.

Man nehme nun an, ein Delirant habe Nachts unter Allerlei anderen Dingen, Steinen, Geräthen, Bäumen n. s. w. ein Paar Hunde, die ihn anfielen, gesehen. Gleichgiltig ob wir ihn nun am nächsten Morgen fragen oder ob er sich ganz von selbst mittheilt, er wird kaum noch von den gleichgiltigen Dingen etwas wissen, die Hunde aber, die ihm Angst eingeflösst haben, wird er vorbringen, da jede Vorstellung, auf der ein affectiver Accent ruht, sich dem Gedächtnisse fester einprägt. Man bemerke, dass hier durchaus nicht in Rose's Sinne von einem Heraus- oder Hereinfragen von Thieren die Rede ist. Die Thiere werden dem Betreffenden nicht fälschlich imputirt, sondern dadurch, dass das Uebrige zur Vernachlässigung kommt, gewinnen die wirklich gesehenen Thiere eine übermässige Bedeutung.

Dieselbe Verschiebung kommt aber ohne jede Befragang bei blossem Beobachten zu Stande. Sieht der Delirant Bäume, Felsen oder Häuser, so wird ihn das ganz ruhig lassen. Auf Thiere wird er aber reagiren. So führt auch die Beobachtung, und zwar die beste, objectivste zu einer Ueberschätzung der Threre.

Es scheinen also einerseits der Affectzustand und die genannten äusseren Bedingungen eine Vermehrung der Thiervisionen im freien Delirium gegenüber den Druckversuchen wirklich zu verursachen, anderseits liegt in der Art, in welcher sich das Innenleben des Deliranten unserer Kenntniss erschliesst - unvermeidlich, nicht in Folge fehlerhafter Beobachtung - ein Factor, welcher zwar nicht ihre absolute, aber ihre relative Frequenz erhöht. Wir bekommen die spontanen Visionen gewissermassen immer erst gesiebt oder filtrirt; in dem Filter bleibt die Mehrzahl der leblosen Dinge zurück und so überwiegt im Filtrat das Lebendige. Schutz.

Gegen diese Verfälschnng liefert nun die Methode durch Druck

Die zweite Differenz war, dass die Druckvisionen durchweg nicht schreckhaft waren. Also muss der beim spontanen Delirium bestehende Affect den dort überwiegend schreckhaften Charakter bedingen. Dazu mögen dann wohl ähnliche Momente kommen wie die, welche uns ein übermässiges Vorherrschen von Thiervisionen vorspiegeln.

Der fehlende Affect, die vorübergehende Sammlung, das mehr oder minder deutliche Gefühl, dass es sich nicht um natürliche Dinge handelt bei den Druckversuchen, erklärt wohl aucb, dass es zu keiner 
Eigenbeziehung, und zu keinem Zusammenhang kommt, dass es also bei Wandelbildern bleibt.

Dass das bei Druck Gesehene kein "Wanken und Schwanken" zeigt, begreift sich wohl aus demselben Moment, welches für die Seltenheit der Thiere herangezogen wurde. Die Druckvisionen entstehen ohne Mitwirkung der Accomodation und der Augenmuskeln. Vermuthlich liegt also in diesen Factoren eine Quelle für das im Spontandelirium so häıfige Anftreten des Phänomens.

Aus den Versuchsergebnissen glaube ich nun Folgendes schliessen zu dürfen: Die Wirkung des Alkohols besteht nicht darin, dass er dem Vorstellungsleben eine Hinneigung zu bestimmten $\operatorname{lnhal}$ ten verleiht. Vielmehr ergiebt sich eine Beeinträchtigung des Vorstellungslebens in der Richtung, dass Sinneserregungen ganzallgemein illusorisch gefälschte Wahrnehmungen auslösen, speciell unter unseren Versuchsbedingungen subjective Empfindungen zu Bildern von Objecten verarbeitet werden.

Die aufgetretene Empfindung erfährt sofort aus dem Innern des Deliranten eine Ergänzung, wobei eine Neigung zur Subsumirung der Erregungen unter bestimmtem Inhalte - etwa Grausiges oder Thiere - nicht besteht. Was vielmehr aus dem geistigen Besitze des Deliranten einigermassen den vorhandenen Empfindungen ähnelt, giebt den assimilirenden Stoff für jene ab. Da dieser geistige Besitz mit den verschiedenen Individuen variirt, so stammt die relative Uebereinstimmung, welche die entstandenen Visionen zeigen (Meteorisches und Gedrucktes) von der Gleichartigkeit der Einwirkungen her. Einerseits ist also die Art der Reizung bestimmend für den Inhalt der Vision, andrerseits die individuelle geistige Vergangenheit des Einzelnen, nicht aber bestimmte allen oder den meisten Deliranten gemeinsame Vorstellungstendenzen.

Wenn dennoch im spontanen Delirium gewisse Inhalte (Thiere und Schreckliches). überwiegen, so liegt das an dem Affect und gewissen äusseren Erregungen.

Schreckliches und Thiere, namentlich letztere, überwiegen aber nicht in dem Grade, in welchem es uns bei einfacher Beobachtung und Befragung erscheint.

Diese Täuschung beruht nicht auf Fehlern des Beobachters, sondern 
auf einer naturgesetzlichen Selbstentstellung, mit der Innenerlebnisse spontan äusseren Ausdruck gewinnen.

Die besprochene elementare Störung der Deliranten, darin bestehend, dass Sinneserregungen, welche normaler Weise subjective Empfindungen hervorrufen müssten, zn Objectbildern verarbeitet werden, bedarf der näheren Kennzeichnung. Der Vorgang ist nicht so zu verstehen, dass der Delirant erst primitive Lichtempfindungen hätte und sie dann bewusst als Dieses oder Jenes deutete. Das entspräche einer Anschaunng, wie sie Rose bekundet. Rose hat den Eindruck, dass es sich bei den Gesichtserscheinungen des Deliranten nur um „leuchtende Kugeln und farbige Punkte" handele. "Dabei bleibt es für den nüchternen Experimentator, der ungebildete Arbeiter reimt sich die Erscheinungen je nach der Stärke seiner Phantasie anders zusammen und macht oft die wunderbarsten Deutungen“. Dann ,weiter als eine Erklärung wird es doch Nichts sein".

Von einer bewussten Deutung oder Erklärung ist nun aber in der Ueberzahl der Fälle keine Rede. Ebensowenig, wie wir die beiden Bilder des Stereoskops zuerst getrennt, flächenhaft, different auffassen und sie dann bewusst zu einem körperlichen Bilde vereinigen, sieht der Alkoholist erst leuchtende Punkte und ,erklärt" sie dann als Objecte. Gewöhnlich sieht der Delirant vielmehr unmittelbar das, was er angiebt. Zuweilen giebt ihm dann das, was so vor ihm steht nun weiter Anlass zu bewusster Deutung, namentlich wenn es sich um Symbole (Buchstaben, Zahlen) handelt.

Im Allgemeinen kann man also von einer „Deutung" des Eindruckes nur im Sinne jener unbewussten Acte sprechen, welche stets in unsere Wahrnehmung eingehen.

Die Regulirung also, welche dem Empfindungscomplex das zugehörige Erinnerungsbild zuweist und so eine adäquate Wahrnehmung herstellt, fehlt beim Deliranten oder ist insufficient. Beim Seelenblinden stösst der sensorische Eindruck auf überbaupt keine assimilirende Vorstellung, beim Deliranten nicht auf die richtige. Bildlich ausgedrückt, sind die Isolirungen, welche normaler Weise die Bahnen von den Sinnes- zu den Erinnerungsvorstellungen trennen, ausgeschaltet.

Auf diese Weise erklärt sich denn auch die illusorische Auffassung der A ussen eindrücke. Statt die zur Erkennung eines Gegenstandes erforderlichen Sinnesdaten zu sammeln, und damit die zu richtiger Assimilation führenden Akte vorzunehmen, verarbeitet der Delirant in dem Trübungsstadium, von welchem die Rede ist, den schon unzureichend gewonnenen Empfindungscomplex illusorisch weiter, genau wie die bei Druck entstandenen Primitivempfindungen. Ebenso haben wir hier eine $\mathrm{Be}$ - 
232 Dr. phil. et med. H. Liepmann, Ueber die Delirien der Alkoholisten etc. stätigung dessen, was wir bei Betrachtung der sensorischen Illusionen vermutheten, dass der Defect des Deliranten - für den Gesichtssinn gesprochen - in der Verarbeiturg des Netzhautbildes, nicht schon in diesem selbst liegt. Denn man wird doch nicht annehmen wollen, dass die Retina des Deliranten gerade so verändert ist, dass Reize, welche auf der Netzhaut des Gesunden leuchtende Punkte hervorrufen, hier Buchstaben, Menschen, Gegenstände abzeichnen.

Wird nun auch durch die Versuche die Annahme nahegelegt, dass viele von den spontanen Trugwahrnehmungen, welche sich nicht als illusorische Auffassung äusserer Eindrücke erweisen lassen, eine illusorische Verarbeitung innerer d. h. entorganischer Erregungen darstellen, also streng genommen auch Illusionen sind, so wage ich doch nicht aus diesen Versuchen schon den Schluss zu ziehen, dass es für alle Sinnestäuschungen der Deliranten der Fall ist. Immerhin gewinnt aber durch die Versuchsergebnisse eine solche Vermuthung an Wahrscheinlichkeit. 